\title{
Analysis of SMOS brightness temperature and vegetation optical depth data with coupled land surface and radiative transfer models in Southern Germany
}

\author{
F. Schlenz ${ }^{1}$, J. T. dall'Amico ${ }^{1}$, W. Mauser ${ }^{1}$, and A. Loew ${ }^{2}$ \\ ${ }^{1}$ Department of Geography, University of Munich, Munich, Germany \\ ${ }^{2}$ Max-Planck-Institute for Meteorology, KlimaCampus, Hamburg, Germany \\ Correspondence to: F. Schlenz (f.schlenz@iggf.geo.uni-muenchen.de)
}

Received: 10 April 2012 - Published in Hydrol. Earth Syst. Sci. Discuss.: 20 April 2012

Revised: 26 August 2012 - Accepted: 5 September 2012 - Published: 5 October 2012

\begin{abstract}
Soil Moisture and Ocean Salinity (SMOS) L1c brightness temperature and L2 optical depth data are analysed with a coupled land surface (PROMET) and radiative transfer model (L-MEB). The coupled models are validated with ground and airborne measurements under contrasting soil moisture, vegetation and land surface temperature conditions during the SMOS Validation Campaign in May and June 2010 in the SMOS test site Upper Danube Catchment in southern Germany. The brightness temperature root-meansquared errors are between $6 \mathrm{~K}$ and $9 \mathrm{~K}$. The L-MEB parameterisation is considered appropriate under local conditions even though it might possibly be further optimised. SMOS L1c brightness temperature data are processed and analysed in the Upper Danube Catchment using the coupled models in 2011 and during the SMOS Validation Campaign 2010 together with airborne L-band brightness temperature data. Only low to fair correlations are found for this comparison $(R$ between 0.1-0.41). SMOS L1c brightness temperature data do not show the expected seasonal behaviour and are positively biased. It is concluded that RFI is responsible for a considerable part of the observed problems in the SMOS data products in the Upper Danube Catchment. This is consistent with the observed dry bias in the SMOS L2 soil moisture products which can also be related to RFI. It is confirmed that the brightness temperature data from the lower SMOS look angles and the horizontal polarisation are less reliable. This information could be used to improve the brightness temperature data filtering before the soil moisture retrieval. SMOS L2 optical depth values have been compared to modelled data and are not considered a reliable source of information about
\end{abstract}

vegetation due to missing seasonal behaviour and a very high mean value. A fairly strong correlation between SMOS L2 soil moisture and optical depth was found $(R=0.65)$ even though the two variables are considered independent in the study area. The value of coupled models as a tool for the analysis of passive microwave remote-sensing data is demonstrated by extending this SMOS data analysis from a few days during a field campaign to a longer term comparison.

\section{Introduction}

The European Space Agency's (ESA) Soil Moisture and Ocean Salinity (SMOS) mission was launched in November 2009 to monitor surface soil moisture and ocean salinity globally with a temporal resolution of 2-3 days and a spatial resolution in the order of $43 \mathrm{~km}$ (Kerr et al., 2010). Soil moisture is derived from multiangular interferometric passive microwave L-band brightness temperature measurements at $1.4 \mathrm{GHz}$ and delivered on an ISEA (icosahedral Snyder equal area projection) grid with a mean distance between grid points of $12.5 \mathrm{~km}$ (Kerr et al., 2010). Potential applications of spaceborne soil moisture products are numerical weather forecasting, land surface hydrology, agricultural applications and climate research (Dirmeyer, 2000; Entekhabi et al., 1999; Bolten et al., 2010). An accuracy target of $0.04 \mathrm{~m}^{3} \mathrm{~m}^{-3}$ soil moisture random error is set for the SMOS L2 soil moisture measurements (Kerr et al., 2010; ESA, 2002). A central question for the validation of SMOS is whether, and under which conditions, this level of accuracy 
can be reached. This paper aims at contributing to answer this question.

It is important to validate remotely sensed soil moisture products properly in order to ensure good product quality that is a prerequisite for the application of the data. This is especially important as SMOS follows a novel technological concept. Validation of passive microwave soil moisture products is challenging due to the mismatch in scale between satellite products and point scale in situ measurements that are typically used for validation of remote-sensing based soil moisture products (Bartalis et al., 2008; Prigent et al., 2005). In situ measurements for satellite validation are usually collected in field campaigns over extended areas and during short periods of time or over longer time spans at few selected measuring locations. In addition to other remotesensing datasets, the outputs of spatially distributed environmental process models can make a valuable contribution to the validation of remotely sensed soil moisture products (Crow et al., 2005; Albergel et al., 2010; Juglea et al., 2010; dall'Amico et al., 2012a). These datasets can help to extend long-term validation activities to larger areas.

Some studies have thoroughly evaluated the SMOS L2 products so far. The performance of the products behaves differently from region to region and changes with time (dall'Amico et al., 2012a; Albergel et al., 2012; Jackson et al., 2012; Parrens et al., 2012; Gruhier et al., 2012). Generally the SMOS performance in Central Europe seems to be degraded compared to other regions of the world. For the Vils test site in the Upper Danube Catchment in southern Germany, that is also the area of interest in this study, Albergel et al. (2012), dall'Amico et al. (2012a) and dall'Amico (2012) have compared SMOS L2 soil moisture products to in situ and modelled reference data. They find mean correlation coefficients of $0.25-0.3$ and a dry bias in the order of $0.23 \mathrm{~m}^{3} \mathrm{~m}^{-3}-0.267 \mathrm{~m}^{3} \mathrm{~m}^{-3}$ for the comparison of SMOS data with in situ data in 2010. For the period April to October 2011 these figures improve considerably with a correlation coefficient of 0.52 and a dry bias of $0.15 \mathrm{~m}^{3} \mathrm{~m}^{-3}$ for the same comparisons (dall'Amico, 2012). For comparisons between modelled soil moisture and SMOS soil moisture, the mean correlation coefficient in the Vils test site for 2011 is 0.54 , the mean bias $0.13 \mathrm{~m}^{3} \mathrm{~m}^{3}$. In Europe the performance of the SMOS L2 soil moisture product was considerably affected by radio frequency interference (RFI) since the launch of SMOS (Albergel et al., 2012; Balling et al., 2011), but the amount of contaminated data has exhibited a decrease due to RFI mitigation efforts and switching off of RFI sources (Oliva et al., 2012). In 2010, several RFI sources were obvious in SMOS L1c data in Germany that have disappeared in 2011. Probably the improvement in SMOS performance in southern Germany can at least partly be attributed to an improvement in the RFI situation. Improvements in the retrieval algorithms may also contribute to this.

Despite these improvements, the validation studies so far show that more work is still necessary to further improve the quality of the SMOS L2 soil moisture products in order to meet the mission target. Therefore, studies should be done where the problems in the SMOS L2 soil moisture product originate from and how improvements could be achieved. Especially the pronounced dry bias in Germany and other regions needs further investigation. It needs to be clarified whether it is RFI-induced or whether it has to do with radiative transfer modelling uncertainties or other retrieval problems. Therefore, it is essential to validate and study the radiative transfer modelling in the L-band of the microwave domain on the SMOS scale. SMOS soil moisture products are inverted through an iterative inversion method from Lband passive microwave observations (Kerr et al., 2010). The radiative transfer model used in the SMOS L2 soil moisture processor is the L-band Microwave Emission of the Biosphere (L-MEB) model (Wigneron et al., 2007) that serves as a forward model in the soil moisture inversion. Uncertainties in the parameterisation of the radiative transfer model can result in errors in the retrieved variables (in most retrievals soil moisture and optical depth). As the L-MEB parameterisations used for the SMOS soil moisture retrieval have been derived mostly from studies with ground or airborne L-band radiometer measurements on the local scale it is possible that scaling issues introduce additional uncertainties. The vegetation optical depth, that is simultaneously retrieved with soil moisture and delivered in the SMOS L2 product, could be a valuable source of information about vegetation characteristics. However, Jackson et al. (2012) concludes that it does not contain reliable information in the US. This could point towards retrieval problems and should also be investigated in other parts of the world.

Few studies have validated and analysed the SMOS L1c products over vegetated surfaces which is important if the radiative transfer modelling abilities in the SMOS processing are to be studied. Examples are Albergel et al. (2011), Montzka et al. (2011), Parrens et al. (2012) and Bircher et al. (2012). Albergel et al. (2011) and Parrens et al. (2012) have shown that there is still potential to improve soil moisture retrievals from SMOS brightness temperatures in southern France. They used calibrated statistical relationships based on reference soil moisture values and additional information like leaf area index (LAI) simulated by a land surface model to produce better soil moisture estimates. Bircher et al. (2012) have compared SMOS L1c and airborne brightness temperatures with modelled brightness temperatures using in situ data as input on different spatial scales on one day in Denmark. They developed an improved L-MEB parameterisation for local conditions. It has been reported, for example, by Bircher et al. (2012) and Panciera et al. (2009) that it is necessary to optimise the parameterisation under local conditions to obtain best results. Bircher et al. (2012) and Hornbuckle et al. (2011) report that brightness temperatures at certain angles may be more reliable than at others. Other studies rely either on ground-based or airborne radiometer 
data as reference with the drawbacks of the mismatch in scale between radiometer and SMOS footprint.

This study aims at assessing how coupled land surface and radiative transfer models can contribute to the validation and analysis of passive microwave remote-sensing data. It is conducted in the highly instrumented Vils test site in the Upper Danube Catchment in southern Germany that has been used as a major SMOS cal/val test site since 2007 (Delwart et al., 2008). Different extensive field campaigns have taken place here that, amongst others, delivered time series of point-like soil moisture station measurements. They are publicly available over the International Soil Moisture Network (ISMN) (Dorigo et al., 2011; http://www.ipf.tuwien.ac.at/insitu/). In addition to that ground-based L-band radiometer measurements and spatially distributed datasets of soil moisture, vegetation and airborne L-band radiometer measurements are available (Schlenz et al., 2012a; dall'Amico et al., 2012b; Schlenz et al., 2012b). The land surface model PROMET (Mauser and Bach, 2009) has been coupled to the radiative transfer model L-MEB to model land surface states in the Upper Danube Catchment on a $1 \mathrm{~km}$ grid as well as the resulting microwave emissions in the L-band. The coupled model is used as a tool for the analysis of the SMOS passive microwave satellite observations.

Possible explanations for the apparent problems in the SMOS L2 soil moisture data in southern Germany are assessed. For this reason, SMOS L1c brightness temperature and L2 vegetation optical depth data are analysed with modelled and airborne data. It is not the intention of this paper to study SMOS L2 soil moisture data as this has thoroughly been done already by dall'Amico et al. (2012a) and dall'Amico (2012). If RFI was responsible for most of the L2 problems, this would be visible in the SMOS L1c brightness temperatures as well. And if SMOS L1c brightness temperatures would perform better than L2 data, this would point towards a problem in the soil moisture retrieval. Retrieved SMOS L2 optical depth values are analysed as they play an important role in the soil moisture retrieval. To study if the parameterisation of the radiative transfer model used for the SMOS soil moisture retrieval works reliably, the radiative transfer modelling is analysed with airborne data from the SMOS Validation campaign 2010 as reference under local conditions. As the SMOS data perform considerably better in 2011 than in 2010 the study concentrates on 2011 data. In addition to 2011 data, data from the SMOS Validation Campaign 2010 are used for model validation and a brief SMOS data analysis as this is the only period with extensive ground and airborne data available.

In Sect. 2, the study area and datasets as well as the models involved in this study are described. This is followed by the description of the methodology. Section 3 details and discusses the results of the model validation, followed by an analysis of the radiative transfer model parameterisation. Next, SMOS L1c brightness temperature data are analysed and compared with airborne brightness temperatures.
Afterwards a longer term comparison with modelled brightness temperatures from April to October 2011 is performed. SMOS L2 optical depth is compared against model results and the SMOS L2 soil moisture product before the main findings are summarised in the conclusions.

\section{Study area and datasets}

The flowchart in Fig. 1 illustrates the context of the different datasets and comparisons in this paper. The coupled models PROMET and L-MEB produce datasets (black) of soil moisture (SM), vegetation optical depth (Tau), and brightness temperatures (BT) that are compared to SMOS data (red). In situ soil moisture (green) and airborne brightness temperatures (blue) are used for model validation. Additional comparisons of airborne brightness temperatures with SMOS L1c brightness temperatures as well as SMOS L2 soil moisture and optical depth values are also carried out.

\subsection{Study area and in situ data}

The study area is the Vils test site in the SMOS test site Upper Danube Catchment in southern Germany. This region has been the subject of a wide range of hydrological, remote sensing and global change studies, e.g., Mauser and Schädlich (1998), Ludwig and Mauser (2000), Bach et al. (2003), Ludwig et al. (2003), Probeck et al. (2005), Loew et al. (2006) and Mauser and Bach (2009). The Vils test site is roughly the size of the mean spatial resolution of SMOS and is situated in the northeast of the Upper Danube Catchment in an undulating terrain that is used agriculturally. It has a temperate humid climate and is considered homogenous with respect to terrain and land cover distribution. This is confirmed by a very low variation of airborne measured brightness temperatures in the area $(<2 \mathrm{~K})$ that are discussed in detail in Sect. 4.1. The test site does not contain large water bodies or cities. The three most important agricultural land cover types are winter wheat, maize and grass. They cover more than $60 \%$ of the area. Based on previous studies (Strasser et al., 1999; Bach and Mauser, 2003; Loew, 2008), this test site has carefully been chosen and used for SMOS calibration and validation (cal/val) studies since 2007 (Delwart et al., 2008). The test site has been instrumented with seven soil moisture profile stations that have been measured between 2007 and 2011. Three additional stations are situated outside the Vils test site. The stations are equipped with horizontally installed probes in several depths. Details about the stations and the related uncertainties can be found in Schlenz et al. (2012a). From the soil moisture stations the hourly $5 \mathrm{~cm}$ measurements from all available probes have been averaged per station and are being used as reference on the local scale in this study. Extensive field campaigns have been carried out here, the most comprehensive one being the SMOS Validation Campaign from 17 May to 8 July 2010. Details of 


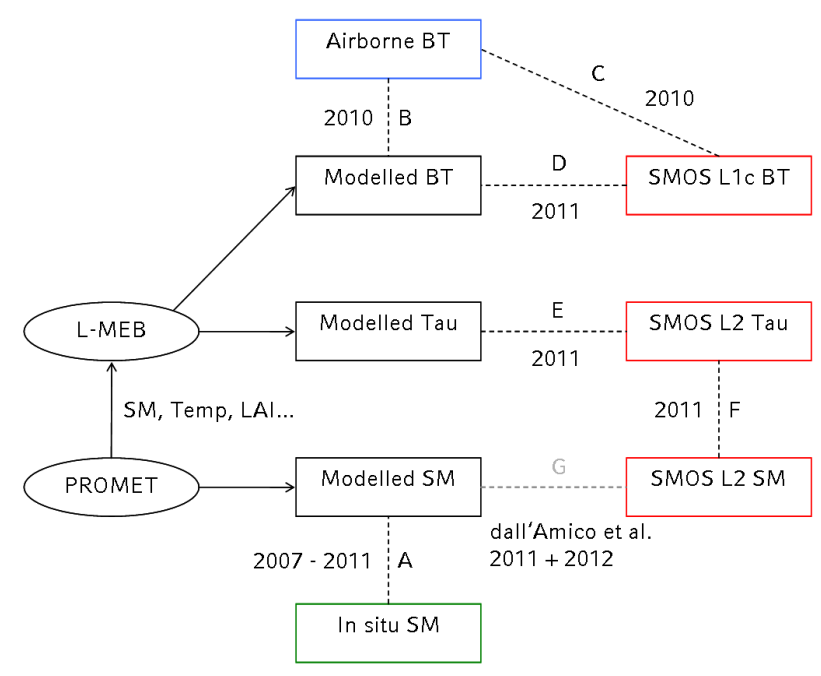

Fig. 1. A flowchart illustrating the different datasets (boxes) and comparisons (dashed lines) in this paper. Black boxes depict modelled datasets provided by the models PROMET and L-MEB, red boxes represent SMOS data, the blue box airborne data and the green box in situ data. The comparisons consist of: (A) land surface model validation with in situ soil moisture (SM) from the years 2007-2011 on the local scale; (B) radiative transfer model validation with airborne EMIRAD brightness temperatures (BT) during the SMOS Validation Campaign 2010 on the SMOS-like scale; (C) analysis of SMOS L1c brightness temperatures with EMIRAD data during the SMOS Validation Campaign 2010; (D) analysis of SMOS L1c with modelled brightness temperatures throughout the vegetation period 2011; (E) analysis of SMOS L2 optical depth (Tau) with modelled optical depth Tau throughout the vegetation period 2011; (F) comparison of SMOS L2 optical depth and SMOS L2 soil moisture throughout the vegetation period 2011.

this campaign are given in dall'Amico et al. (2012b). During this field campaign airborne L-band radiometer measurements were performed together with more than 9000 soil moisture and comprehensive vegetation parameter measurements that were collected in five selected focus areas sized roughly 3 by $7 \mathrm{~km}$ and distributed throughout the test site. The datasets that are averaged and compared on basis of the focus areas are considered as reference for the regional scale in the Vils test site. Contrasting soil moisture, temperature and vegetation conditions were observed in the course of the campaign (focus area mean values of soil moisture varied between $0.17 \mathrm{~m}^{3} \mathrm{~m}^{-3}$ and $0.39 \mathrm{~m}^{3} \mathrm{~m}^{-3}$, air temperatures during overflight were between $7^{\circ} \mathrm{C}$ and $18^{\circ} \mathrm{C}$, vegetation heights ranged between $7 \mathrm{~cm}$ and $79 \mathrm{~cm}$ ).

The analyses in this study concentrate on the ISEA grid point 2027099 that is located in the centre of the Vils test site and the furthest away from any open water bodies. Two neighbouring grid points in the Vils test site have the IDs 2026586 and 2026587 and are also subject to analyses in this study. Due to the homogeneity of the Vils test site the in situ and airborne measurements from the field campaigns are considered to be representative for the whole Vils test site. Figure 2 gives an overview of the Vils test site.

\subsection{Airborne data}

During the SMOS Validation Campaign the airborne L-band radiometer EMIRAD 2 (owned by the technical University of Denmark; Skou et al., 2010) was flown on five days onboard the Skyvan aircraft over the Vils test site to measure brightness temperatures emitted by the land surface over roughly $20 \%$ of the central SMOS pixel (dall'Amico et al., 2012b) around SMOS morning overpass time. EMIRAD is a thoroughly validated radiometer that has been used in a variety of studies (Skou et al., 2010; Delwart et al., 2008) and is, therefore, used as reference in this study. EMIRAD has an antenna system consisting of two Potter horns, one pointed nadir and one $40^{\circ}$ aft and has a footprint size of about $1.5 \mathrm{~km}$ for the nadir antenna and $2 \mathrm{~km}$ for the $40^{\circ}$ looking antenna for an average flight altitude of $2 \mathrm{~km}$ above ground. The data processing is described in Schlenz et al. (2012a) and involved RFI filtering with RFI flags that were provided with the data and a threshold filtering using the same threshold values as for the SMOS data (see Sect. 2.3). Due to the measurement principle of EMIRAD and the low flight altitude of the aircraft resulting in a rather small field-of-view, this dataset is far less influenced by RFI than SMOS. After processing the data were available for the two look angles $0^{\circ}$ and $40^{\circ}$ for vertical and horizontal polarisation. A detailed description of the airborne campaign dataset is given by dall'Amico et al. (2012b). A systematic bias of $\sim 3.5 \mathrm{~K}$ was observed for the EMIRAD $40^{\circ}$ vertical channel throughout the SMOS Validation Campaign 2010 as reported in Bircher et al. (2012). As this bias is only reported by one author and, therefore, needs further investigation it is not corrected for but discussed in Sect. 4.1.

For further comparisons the distributed EMIRAD data from the flight lines were mapped onto the ISEA grid by averaging for every ISEA grid point with the nearest neighbour method. This dataset is referred to as a SMOS-like scaled dataset in this study.

\subsection{SMOS data}

The operational SMOS L1c and L2 data, that are being used in this study, are delivered on the ISEA grid with a mean distance between grid points of about $12.5 \mathrm{~km}$, although the data have a mean resolution in the order of $43 \mathrm{~km}$ (Kerr et al., 2010). SMOS L1c brightness temperatures are valid for the whole SMOS footprint, which actual size is dependent on the incidence angle $\left(0-55^{\circ}\right)$ and, therefore, changes from one observation to the other. The SMOS L2 soil moisture and optical depth products are only considered valid for low vegetation within the footprint. Only for this nominal landcover class is the soil moisture retrieval carried out. Details about the geometry and other properties of the data products 


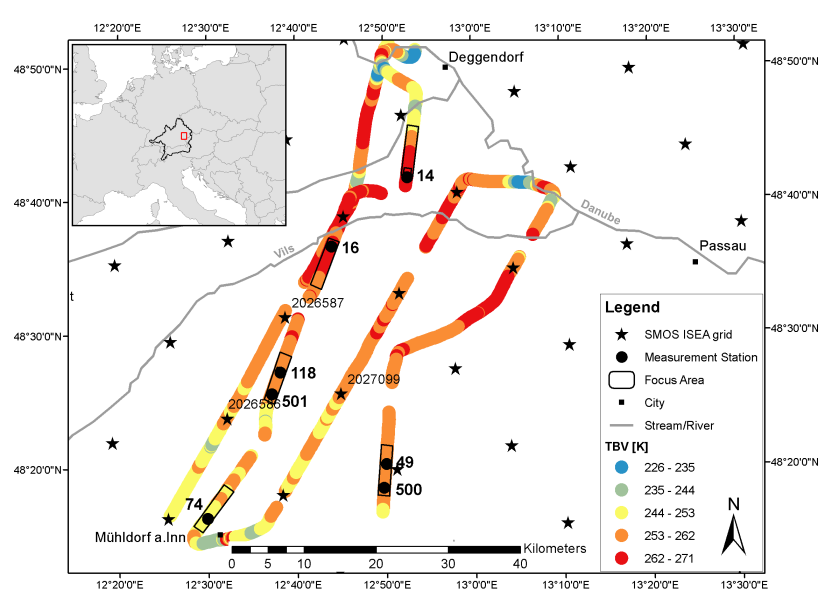

Fig. 2. The Vils test site with focus areas, soil moisture measuring stations, SMOS ISEA IDs and EMIRAD TBV data from 12 June 2010. The small overview map in the upper left corner shows the location of the Upper Danube Catchment (black) and the Vils test site (red) in Central Europe.

can be found in the Algorithm Theoretical Basis Document (ATBD) of the SMOS L2 Soil Moisture Processor (Kerr et al., 2011). Only SMOS data from morning orbits (around 06:00 a.m. local time) are used to avoid uncertainties related to differences between morning and evening overpasses that have been found by Rowlandson et al. (2012).

In order to make the SMOS L1c data usable a comprehensive data processing chain has been developed and set up that helps to reduce the noise in the data by erasing unrealistic outliers and makes it easier to interpret. The processing consists of filtering, geometric and Faraday rotation and an incidence angle based analysis. The processing has been adapted from the official SMOS L2 soil moisture processing described in Kerr et al. (2011). In a first step observations that are RFI flagged or do not fulfil the spatial resolution requirements because the footprint is too large or elongated are filtered out by applying:

$\frac{\operatorname{axis} 1}{\operatorname{axis} 2}>1.5$

and

$\sqrt{4 \cdot \operatorname{axis} 1 \cdot \operatorname{axis} 2}>3025$

where axis1 and axis2 are the half lengths of the major and minor axis of the $3 \mathrm{~dB}$ contour of the near elliptical SMOS footprint. Afterwards, several RFI filtering techniques are performed to detect strong RFI. These include a threshold filtering deleting all brightness temperatures above $300 \mathrm{~K}$ and below $200 \mathrm{~K}$ as only land surfaces are considered. The upper and lower thresholds for the imaginary part of full polarised brightness temperatures are $-50 \mathrm{~K}$ and $50 \mathrm{~K}$, respectively. Another test compares the amplitudes of the brightness temperatures to their expected range with:
$50<\sqrt{\mathrm{TB}_{X}^{2}+\mathrm{TB}_{Y}^{2}}<500$

and filters out data exceeding these thresholds. Additional techniques are applied to filter for soft RFI. These are based on the fourth Stokes parameter ST4 that is required to be below the threshold of $50 \mathrm{~K}$ and the mean value of the halved first Stokes parameter of all observations for one pixel $\langle\mathrm{TBS} 1\rangle=0.5 \cdot\left(\mathrm{TB}_{X}+\mathrm{TB}_{Y}\right)$. Following condition needs to be fulfilled to pass the test for brightness temperature observations:

$(\mathrm{TBS} 1-\langle\mathrm{TBS} 1\rangle)>5.0+4.0 \cdot \mathrm{DTB}_{X}$

where $\mathrm{DTB}_{X}$ is the radiometric uncertainty related to $\mathrm{TB}_{X}$. This test is only reasonable in homogenous areas where brightness temperature variations within one pixel do not arise from a large surface heterogeneity (e.g., coastlines). Most of these threshold have been taken from Kerr et al. (2011) while some are more strict than the values used in the SMOS L2 processing. They have been tested with airborne and SMOS brightness temperatures and proven to be valuable under local conditions (dall'Amico et al., 2012b).

L1c data are delivered as top of atmosphere (TOA) brightness temperatures in antenna geometry that need to be rotated to enable a comparison with brightness temperatures on the Earth's surface which is performed in the next step. The necessary rotations comprise a geometric rotation to correct for the transformation from antenna to Earth surface reference frame and the Faraday rotation to correct for the influence of the atmosphere on the brightness temperatures. The rotations are detailed in Kerr et al. (2011). After the rotations, the vertical and horizontal polarised brightness temperatures are averaged into $10^{\circ}$ bins that are centred around the designated angle to enable an incidence angle based analysis. A similar approach was chosen by Parrens et al. (2012).

This processing reduces the noise in the data considerably, but outliers that are probably related to RFI are still present in the data. The SMOS data is especially RFI-prone due to the interferometric measurement principle and the large field-ofview of SMOS that can lead to RFI sources disturb SMOS data over several hundreds of kilometres.

The SMOS L2 optical depth data have been processed analogue to the SMOS L2 soil moisture processing as described in dall'Amico et al. (2012a). It involves a filtering using the data quality index value (DQX) and the flags indicating RFI, precipitation and whether a retrieval has been successfully produced (FL_RFI_Prone_H, FL_RFI_Prone_V, FL_RAIN, FL_NO_PROD) (Kerr et al., 2011). This processing reduces noise in the data by deleting some unrealistic outliers, but there are still outliers left in the data that are probably connected to RFI that is not detected by the methods and flags used. 


\section{Methods}

\subsection{Coupled land surface and radiative transfer modelling}

The hydrological land surface model PROMET (PROcesses of Mass and Energy Transfer; Mauser and Bach, 2009) and the microwave emission model L-MEB (L-band emission of the biosphere; Wigneron et al., 2007) have been coupled to model land surface states (e.g., soil moisture, temperatures, vegetation parameters) and the resulting microwave emission. Two publications have already validated the models and discussed the uncertainties related to this modelling approach thoroughly. While Schlenz et al. (2012a) have focussed on the validation and uncertainties related to the land surface modelling from point to SMOS-like scale in the Upper Danube Catchment and brightness temperature modelling on the SMOS-like scale in the Vils test site, Schlenz et al. (2012b) have analysed the radiative transfer modelling on the point scale in a test site roughly $100 \mathrm{~km}$ southwest of the Vils test site. Therefore, it is referred to these publications for a more thorough discussion of the related uncertainties.

\subsubsection{Land surface model PROMET}

In the present study, the hydrological land surface model PROMET is used to simulate fields of land surface states with an hourly resolution on a $1 \mathrm{~km}$ grid in the Upper Danube Catchment. A detailed description of the model physics is given by Mauser and Bach (2009) and Mauser and Schädlich (1998). The model describes all relevant water and energy fluxes related to the radiation balance, vegetation, soil, snow and land-surface-atmosphere exchange processes. It is spatially distributed and based on high resolution spatial input data like land cover and soil maps and meteorological forcing data from station networks or regional climate models. In our case the meteorological station network delivering the meteorological forcing consists of more than 130 stations operated by the Bavarian State Research Center for Agriculture. The land cover map has been derived from high resolution satellite imagery and statistical information on community level, the soil map is taken from a combination of the European and German soil map and regional soil information supplied by the BÜK (1997). The soil moisture dynamics modelling is done in PROMET with a 4-layer soil model based on an explicit solution of the Richards equation for flow in unsaturated media (Philip, 1957) while the soil water retention model of Brooks and Corey (1964) is used to relate soil suction head to soil moisture content. The 4 soil compartments were selected to be situated at $0-2,2-15,15-50$ and $50-150 \mathrm{~cm}$ depth for this study. For all comparisons between modelled and measured soil moisture the second soil layer is used, as its depth corresponds to the depth where most soil moisture measurements were performed. The average of the first two layers is used for brightness temperature modelling and SMOS comparisons as the penetration depth of microwaves in the L-band is typically $5 \mathrm{~cm}$ (Kerr et al., 2010). The model has been validated in different test sites on different scales by Mauser and Schädlich (1998), Ludwig and Mauser (2000), Mauser and Bach (2009), Loew et al. (2006), Strasser and Mauser (2001), Pauwels et al. (2008) and Muerth (2008) evaluated the soil temperature modelling abilities of PROMET in the Upper Danube Catchment with measurements and remote-sensing data.

For the analysis of the 2011 dataset the dynamic vegetation model within PROMET was used. It models the vegetation development dynamically depending on the soil and weather characteristics for all individual pixels. Plant development is simulated with a 2 layer canopy model, which iteratively closes the energy balance for the sub-canopy soil surface and each layer of the canopy and, thereby, produces a canopy radiation temperature. Details are given in Hank (2008). The modelled vegetation parameters phenology, vegetation height, vegetation biomass and leaf area index (LAI) of this model, which evolve dynamically according to the course of the weather, have been compared to ground measurements with very good results by Hank (2008). These comparisons were carried out in the centre of the Upper Danube Catchment for several test sites on wheat, oat, maize and grassland during several years Hank (2008) assessed, for example, the modelled LAI with measurements resulting in a mean $R$ of $0.96(0.96)$ and a mean Nash-Sutcliffe coefficient of 0.83 (0.87) for wheat (maize).

Schlenz et al. (2012a) have compared modelled soil moisture from PROMET with soil moisture measurements on different scales. The measurements were conducted on the local scale at seven soil moisture measuring stations in the Vils test site and two additional ones outside the test site that have been measuring between November 2007 and November 2010. On the regional scale measurements were performed in the five focus areas that are considered representative for the central SMOS grid point in the Vils test site with handheld probes during the SMOS Validation Campaign 2010 on 8 days between May and July 2010 and averaged per focus area (Schlenz et al., 2012a). They concluded that the uncertainties of the soil moisture modelling decrease from local to regional scale with a mean root-meansquared error (RMSE) of $0.094 \mathrm{~m}^{3} \mathrm{~m}^{-3}$ on the local scale and $0.040 \mathrm{~m}^{3} \mathrm{~m}^{-3}$ on the regional scale. The mean $R$ on the local scale is 0.77 . A bias leads to high RMSE values especially in wet conditions which leads to an underestimation in the reproduction of the seasonal soil moisture dynamics through PROMET.

A detailed analysis of the soil moisture modelling uncertainties described by Schlenz et al. (2012a) showed that four of the five stations with the highest RMSE values are located on the same soil type, silt loam. As the laboratory soil texture analysis from soil samples taken at these stations differed substantially from the soil texture used in the model parameterisation the soil parameterisation of the model was 
improved for this soil type. This was based on the laboratory results. The results are detailed in Sect. 4.1.

Loew and Schlenz (2011) have used an extended version of the triple collocation method (Miralles et al., 2010) to assess relative soil moisture errors of PROMET, the in situ measurements from the stations in the UDC and coarse scale satellite soil moisture products. They conclude that the soil moisture random error of PROMET is better than $0.025 \mathrm{~m}^{3} \mathrm{~m}^{-3}$ on the SMOS scale which is consistent with similar findings of Schlenz et al. (2012a).

For further comparisons with SMOS data the distributed model data was mapped onto the ISEA grid by averaging for every ISEA grid point with the nearest neighbour method.

\subsubsection{Radiative transfer model L-MEB}

The microwave emission model L-MEB, which is also part of ESA's SMOS Level 2 soil moisture processor, is used to simulate L-band brightness temperatures from the continuous soil vegetation layer in the Upper Danube Catchment on a $1 \mathrm{~km}$ resolution. A comprehensive description of the model is given by Wigneron et al. (2007). This zero-order Tau $(\tau)$ - Omega $(\omega)$ radiative transfer model uses PROMET soil moisture, soil surface temperature and LAI fields as input for the modelling. The polarised ( $p=h, v)$ brightness temperature $\mathrm{TB}_{\mathrm{P}}[\mathrm{K}]$ is calculated through a sum of the three terms (1) soil emission attenuated (scattered and absorbed) by the vegetation, (2) direct vegetation emission and (3) vegetation emission reflected by the soil and attenuated by the vegetation again:

$\mathrm{TB}_{\mathrm{P}}=\left(1-\omega_{p}\right)\left(1-\gamma_{p}\right)\left(1+\gamma_{p} r_{\mathrm{Gp}}\right) T_{\mathrm{C}}+\left(1-r_{\mathrm{Gp}}\right) \gamma_{p} T_{\mathrm{G}}$

where $\gamma_{p}$ is the vegetation attenuation factor $[-]$ and $\omega_{p}$ is the vegetation single scattering albedo [-]; $T_{\mathrm{G}}$ and $T_{\mathrm{C}}$ are the effective temperature of the ground and the canopy $[\mathrm{K}]$, respectively. $r_{\mathrm{Gp}}$ is the reflectivity of the rough soil [-] which is typically described as a function of the Fresnel reflectivities of a smooth surface, modified by a surface component. The vegetation attenuation factor $\gamma_{p}$ is described as a function of the vegetation optical depth $\tau$ at nadir and the observation angle. The effective temperature of the ground, $T_{\mathrm{G}}$, is calculated from the surface and deep $(50 \mathrm{~cm})$ soil temperatures by the approach of Wigneron et al. (2007) and $T_{\mathrm{C}}$ is approximated by PROMET's air temperature. The vegetation optical depth is calculated using LAI values from PROMET and the parameters $b^{\prime}$ and $b^{\prime \prime}$ with the approach of Wigneron et al. (2007). The optical depth of forests is fixed to a defined value. The roughness parameter $H_{\mathrm{R}}$ over grass is chosen as a function of soil moisture (Saleh et al., 2009). Together with $Q_{\mathrm{R}}, \mathrm{NR}_{p}$ and $\mathrm{tt}_{p}$ it is part of the surface component used to modify the Fresnel reflectivity.

The land cover specific L-MEB parameters used for the modelling are summarised in Table 1, they are in line with the parameters used by Wigneron et al. (2007), Saleh et al. (2007) and Grant et al. (2007) and have been taken from a compilation of parameterisations of L-MEB based on experimental studies (J.-P. Wigneron, personal communication, 2007) that forms the basis of the SMOS L2 processor parameterisation. These parameters agree mostly with the default parameters that are being used in the operational version of the SMOS L2 processor for Central European Crops (Kerr et al., 2011).

As different authors have reported that it might be necessary to parameterise L-MEB locally to obtain optimal results (Panciera et al., 2009; Bircher et al., 2012), the radiative transfer modelling abilities of the coupled models PROMET and L-MEB have been validated on the local scale by Schlenz et al. (2012b) near Munich over a rape field and on the SMOS scale by Schlenz et al. (2012a) in the Vils test site.

Schlenz et al. (2012b) have developed a new L-MEB parameterisation for winter rape and tested the suitability of it for soil moisture retrievals from ground based multiangular L-band brightness temperature data of a ELBARA II radiometer (Schwank et al., 2009) situated in Puch near Munich in the Upper Danube Catchment. They also analysed the sensitivity of L-MEB to different parameterisations under local conditions. They conclude that the soil moisture retrieval with L-MEB works satisfyingly over rape and that the optical depth parameterisation and the roughness parameterisation are crucial for the radiative transfer modelling. These results are consistent with a variety of studies that stress the importance of correct optical depth and roughness parameterisation for radiative transfer modelling, e.g., Bircher et al. (2012) and Panciera et al. (2009). As ELBARA II has a footprint size in the order of $40-350 \mathrm{~m}^{2}$ these comparisons are considered as local scale comparisons. The rape parameterisation developed by Schlenz et al. (2012b) has been added to Table 1 .

To test the suitability of the L-MEB parameters in the Vils test site (Schlenz et al., 2012a) have compared modelled brightness temperatures to airborne measurements of brightness temperatures from the airborne L-band radiometer EMIRAD (Skou et al., 2010). This has been done on basis of the SMOS ISEA grid for the look angles $0^{\circ}$ and $40^{\circ}$ for five days during the SMOS Validation Campaign 2010. They concluded that the model performs very well on three of the campaign days while on two days there are deviations between model results and measurements. RMSE values for this comparison at the central ISEA ID in the Vils test site (2027099) are $16.52 \mathrm{~K}$ and $13.14 \mathrm{~K}$ for horizontal and vertical polarisation of the $40^{\circ}$ look angle and $12.97 \mathrm{~K}$ and $12.09 \mathrm{~K}$ for horizontal and vertical polarisation of the $0^{\circ}$ look angle, respectively. These comparisons are resumed in Sect. 4.1 and thoroughly discussed in context with the new results obtained from the improved land surface model using a dynamic vegetation model. 
Table 1. The land cover specific L-MEB parameters used for the radiative transfer modelling.

\begin{tabular}{llllllll}
\hline & $H_{R}$ & $Q_{R}$ & $\mathrm{NR} h / \mathrm{NR} v$ & $\mathrm{tt} h / \mathrm{tt} v$ & $\omega h / \omega v$ & $b^{\prime}$ & $b^{\prime \prime}$ \\
\hline Bare soil & 0.1 & 0 & $0 /-1$ & $1 / 1$ & $0 / 0$ & 0 & 0 \\
Crops general & 0.15 & 0 & $0 /-1$ & $1 / 1$ & $0 / 0$ & 0.05 & 0 \\
Wheat & 0.1 & 0 & $0 /-1$ & $1 / 8$ & $0 / 0$ & 0.035 & 0 \\
Corn & 0.6 & 0 & $0 /-1$ & $2 / 1$ & $0.05 / 0.05$ & 0.05 & 0 \\
Grass & $1.3-1.13 \cdot \mathrm{SM}$ & 0 & $1 / 0$ & $1 / 1$ & $0 / 0.05$ & 0.04 & 0.03 \\
Coniferous & 1.2 & 0 & $1.8 / 2$ & $0.9 / 0.8$ & $0.07 / 0.07$ & $\tau \mathrm{NAD}=0.65$ & 0 \\
Deciduous & 1. & 0 & $1 / 2$ & $0.6 / 0.5$ & $0.07 / 0.07$ & $\tau \mathrm{NAD}=1$ & 0 \\
Rape & 0.93 & 0 & $0 /-1$ & $1 / 1$ & $0 / 0$ & 0.09 & 0.08 \\
\hline
\end{tabular}

\subsection{SMOS data analysis}

After the performance of the L-MEB parameterisation under local conditions has been analysed with a comparison between modelled and airborne brightness temperatures these airborne brightness temperatures are also compared to SMOS L1c data during the SMOS Validation Campaign 2010. Afterwards SMOS L1c data are compared to modelled brightness temperatures for a range of look angles for the year 2011. All SMOS data comparisons are done on the basis of the ISEA grid to which the airborne and model datasets have been mapped.

\subsubsection{Comparison of SMOS L1c with airborne brightness temperatures during the SMOS Validation Campaign 2010}

During the SMOS Validation Campaign 2010 airborne brightness temperatures are available for the Vils test site from the EMIRAD radiometer for five days on which SMOS morning overpasses have taken place. Unfortunately only on two of those days SMOS L1c data with sufficient quality are available, and only on 17 June a value for the $0^{\circ}$ look angle is available. Those datasets of EMIRAD and SMOS measurements are compared for the five campaign days at the central ISEA grid point in the Vils test site for the two EMIRAD look angles $0^{\circ}$ and $40^{\circ}$. The EMIRAD data was averaged using a simple mean as this method was also applied by Bircher et al. (2012) successfully for a similar dataset. The results are presented in Sect. 4.2.1.

\subsubsection{Comparison of SMOS data with modelled data in 2011}

To enable a longer term analysis of SMOS L1c brightness temperatures under varying soil moisture and vegetation conditions, they are compared to modelled brightness temperatures from April to October 2011. The terminology longer term here stresses the difference to the short term analysis that consisted of only several days during the SMOS Validation Campaign. For the ISEA grid points in the Vils test site these comparisons are performed for the angles $10^{\circ}, 20^{\circ}$, $30^{\circ}, 40^{\circ}$ and $50^{\circ}$ for both polarisations. They are presented and discussed in Sect. 4.2.2.

To study whether the optical depth values in the SMOS L2 soil moisture product that are obtained during the soil moisture retrieval contain valuable information, they are compared to modelled values of optical depth using vegetation parameters from the dynamic vegetation model PROMET for 2011. The time series for every ISEA grid point is compared to SMOS optical depth values. To test whether there is a relation between retrieved SMOS L2 soil moisture and optical depth the correlation between both datasets for 2011 is calculated. The results for the ISEA IDs in the Vils test site are presented and discussed in Sect. 4.3.

\section{Results and discussion}

\subsection{Model validation and L-MEB parameterisation under local conditions}

Through the use of the new parameterisation and other model improvements the deviation between modelled and measured soil moisture decreased clearly. The mean RMSE of the four stations with the highest deviations decreased from $0.122 \mathrm{~m}^{3} \mathrm{~m}^{-3}$ to $0.057 \mathrm{~m}^{3} \mathrm{~m}^{-3}$ while the mean $R$ increased from 0.72 to 0.84 for the same timeframe as the original analysis. Overall this new parameterisation leads to a mean RMSE over all nine stations that could be used for this analysis of $0.065 \mathrm{~m}^{3} \mathrm{~m}^{-3}$ and a mean $R$ of 0.84 for the same timeframe as the original analysis. Applied to the whole test site this new parameterisation leads to a slightly improved RMSE of $0.039 \mathrm{~m}^{3} \mathrm{~m}^{-3}$ for the focus area averages on the regional scale. Figure 3 shows the comparison of the modelled and measured $5 \mathrm{~cm}$ soil moisture mean of the five soil moisture stations that are within a $20 \mathrm{~km}$ radius around SMOS ID 2027099 for 2011 . The mean $R$ for this comparison is 0.78 , the mean RMSE $0.043 \mathrm{~m}^{3} \mathrm{~m}^{-3}$.

Through the usage of the improved land surface model now using a dynamic vegetation model the error values for the comparison of modelled and airborne measured brightness temperatures from the SMOS Validation Campaign 2010 have decreased substantially to $8.39 \mathrm{~K}$ and $8.98 \mathrm{~K}$ for 


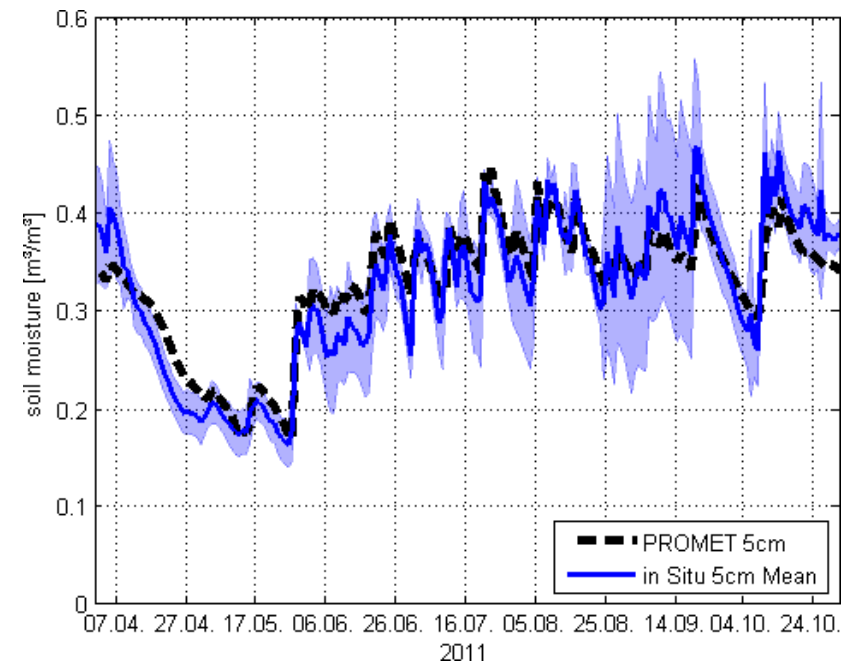

Fig. 3. A comparison of modelled and measured soil moisture in $5 \mathrm{~cm}$ depth from April to October 2011. Shown are the mean values of the five soil moisture stations that are within $20 \mathrm{~km}$ radius of the SMOS ID 2027099. \pm one standard deviation are indicated for the in Situ data.

horizontal and vertical polarisation of the $40^{\circ}$ look angle and $6.80 \mathrm{~K}$ and $6.45 \mathrm{~K}$ for the horizontal and vertical polarisation of the $0^{\circ}$ look angle, respectively. To illustrate these results, Fig. 4 compares modelled brightness temperatures in the Vils test site on five days during the SMOS Validation Campaign 2010 with measurements from the airborne L-band radiometer EMIRAD for the $40^{\circ}$ look angle. The error bars indicate the standard deviations from the averaging.

The vertically polarised brightness temperature shows a relatively constant offset in the order of $5-10 \mathrm{~K}$ while the horizontally polarised brightness temperature does not. These deviations are considered small considering the uncertainties related to the modelling, the airborne measurements and possible scaling effects. Possibly the L-MEB parameterisation could further be optimised. No systematic bias is observed for the $0^{\circ}$ look angle (not shown), the RMSE is largely determined by deviations on the last day.

It is considered promising that on four of the five days the model works reliably despite contrasting soil moisture, temperature and vegetation conditions. This leads us to the overall conclusion that the coupled models work reliably and the parameterisations chosen for L-MEB are appropriate under the local conditions. Especially the roughness and vegetation optical depth parameterisations seem to be appropriate as the model performance does not change significantly during the first four days even though vegetation grows strongly during this time. For example, the mean vegetation height of all wheat fields in the focus areas increases from $40.2 \mathrm{~cm}$ to $77.9 \mathrm{~cm}$ during those four flight days. Growing vegetation increases the importance of correct vegetation parameterisation through an increase in vegetation optical depth (Woodhouse, 2006). An incorrect soil roughness parameterisation

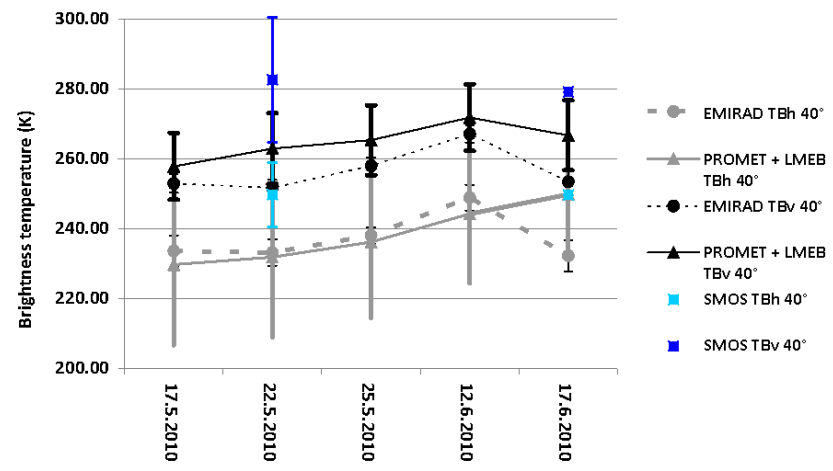

Fig. 4. A comparison of modelled (triangles) and measured (EMI$\mathrm{RAD}$, circles) $40^{\circ}$ brightness temperatures on the five campaign days of the SMOS Validation Campaign 2010 based on the central ISEA grid point in the Vils test site (2027099). For completion the SMOS L1c brightness temperatures for $40^{\circ}$ are also plotted for the two days that are available (squares). All datasets are valid roughly for 06:00 a.m. local time. The model and EMIRAD values represent the mean value of the spatially averaged distributed data that were mapped to this ISEA ID. Error bars indicate \pm one standard deviation from the spatial averaging (models and EMIRAD) and the SMOS data quality index (SMOS), respectively.

would lead to a clear offset between model output and measurements in all angles and polarisations, especially at the beginning.

On the last day there is a considerable deviation between measurements and model output, that is also apparent for the $0^{\circ}$ look angle (not shown). While the measured brightness temperatures decrease by about $15 \mathrm{~K}$, the modelled vertically polarised brightness temperature decreases by only about $4 \mathrm{~K}$ and the horizontally polarised brightness temperature increases by about $5 \mathrm{~K}$. It is not possible to give a simple explanation for this deviation between model output and measurements. Modelled soil moisture and temperatures do not show any abnormality (soil moisture deviations between model and field measurement for the whole Vils test site are below $0.03 \mathrm{~m}^{3} \mathrm{~m}^{-3}$ as for most of the other days, too). When compared to the earlier days the vegetation growth is considerably smaller between the last two days, all of the three most important plants wheat, maize and grass grow less than $8 \mathrm{~cm}$ on average in this time frame. A feature that is different on the last day in comparison to all other days is that the upper soil layer is very wet and that standing water is present in the area due to considerable precipitation events shortly before the EMIRAD overflight. Possibly interception is still present and the soil moisture gradient in the upper soil layer is high. This may be part of an explanation for the distinct behaviour of the brightness temperatures on this day. It is known that high soil moisture gradients in the upper soil layer, standing water and interception after precipitation events can lead to problems in the radiative transfer modelling which has also been reported by Jackson et al. (2012) and Rowlandson et al. (2012). Therefore, the observed deviation does 


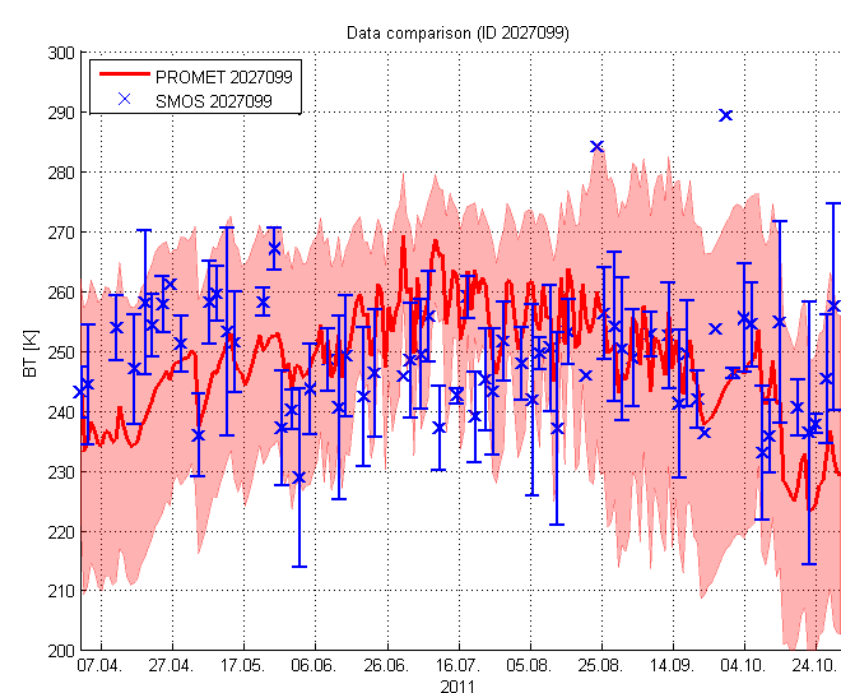

Fig. 5. The time series of modelled and SMOS L1c brightness temperatures for April to October 2011 for the $20^{\circ}$ look angle and horizontal polarisation for the central ISEA grid point in the Vils test site. Error bars indicate \pm one standard deviation for angular (SMOS) and spatial (model) averaging.

not necessarily point toward a parameterisation problem, but should be further investigated. Overall the L-MEB parameterisation works very well under contrasting conditions and is considered appropriate under local conditions so that no further investigations on the parameterisation are performed. Yet, it is possible that the parameterisations could further be optimised under local conditions.

\subsection{Analysis of SMOS L1c data}

\subsubsection{Comparison with airborne brightness temperatures during the SMOS Validation Campaign 2010}

All $40^{\circ}$ SMOS observations in Fig. 4 are larger than their EMIRAD counterpart while the $0^{\circ}$ observation is lower. The RMSEs are $17.02 \mathrm{~K}$ and $28.05 \mathrm{~K}$ for the horizontal and vertical polarisation of the $40^{\circ}$ angle, respectively. For the $0^{\circ}$ angle (not shown here) the RMSEs are $11.12 \mathrm{~K}$ and $11.55 \mathrm{~K}$ for the horizontal and vertical polarisation, respectively. SMOS data show the expected behaviour with vertically polarised brightness temperatures being higher than the horizontally polarised ones for $40^{\circ}$ and both being essentially the same for $0^{\circ}$. But a RMSE between $11.12 \mathrm{~K}$ and $28.05 \mathrm{~K}$ can be considered a substantial deviation that may be attributed at least partly to RFI problems. Due to the small sample size this comparison is not considered reliable enough to draw further conclusions. Of course this comparison involves some approximations related to the different geometries of the two datasets. As the SMOS L1c data are valid for a larger area than what is being mapped to each ISEA grid point in a nearest neighbour mapping approach, they are also valid for a

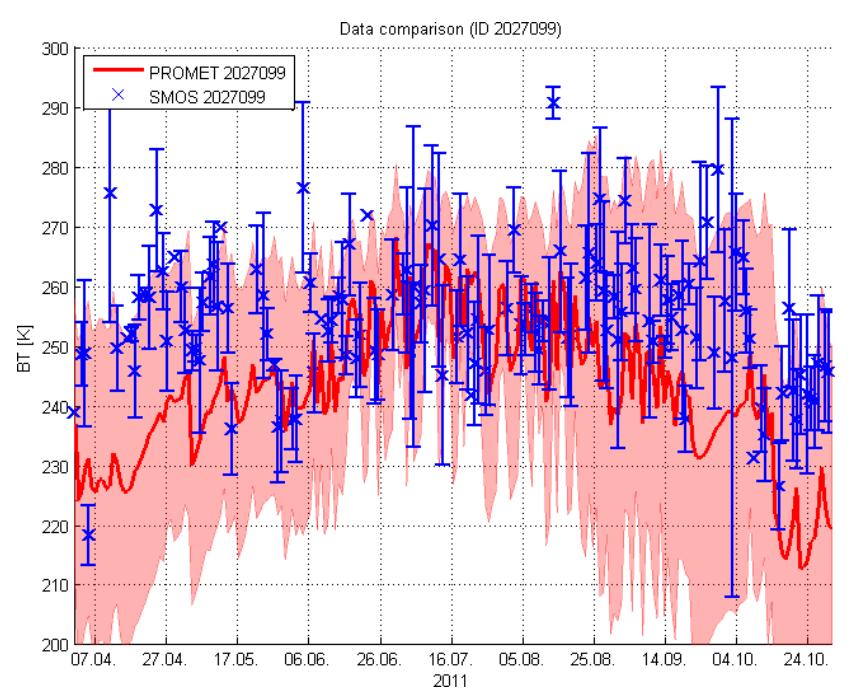

Fig. 6. The time series of modelled and SMOS L1c brightness temperatures from April to October 2011 for the $40^{\circ}$ look angle and horizontal polarisation for the central ISEA grid point in the Vils test site. Error bars indicate \pm one standard deviation for angular (SMOS) and spatial (model) averaging.

larger area than the EMIRAD data. But as the Vils test site is very homogenous concerning soil, land cover, climate and topography it is assumed that this difference of geometries plays a very small role. In addition to that the centre of the SMOS footprint contributes more to the SMOS brightness temperature value than the edges due to the antenna pattern. The homogeneity of the test site is confirmed by the low variation of EMIRAD brightness temperatures and standard deviations of the neighbouring ISEA grid points. If a mean value of the three Vils ISEA grid points 2027099, 2026586 and 2026587 is calculated the deviation of this value from the 2027099 value never reaches $2 \mathrm{~K}$. The homogeneity of the area is also the justification for the assumption that the EMIRAD data are representative for the whole area even though the EMIRAD flight lines do not cover the whole area. The flight pattern was planned carefully in order to best represent the variability present in the Vils test site.

\subsubsection{Comparison with modelled brightness temperatures for the year 2011}

To study SMOS L1c brightness temperatures in different seasons a longer term comparison of SMOS L1c brightness temperatures with modelled brightness temperatures has been performed for the central ISEA grid point for April to October 2011. The corresponding statistics are summarised in Table 2 for the look angles $10^{\circ}, 20^{\circ}, 30^{\circ}, 40^{\circ}$ and $50^{\circ}$ and both polarisations, respectively.

It is apparent that the correlations between both datasets are only low to fair ( $R$ between $0.1-0.41$ ) with RMSE values around 11-22 K. For horizontal polarisation correlations 


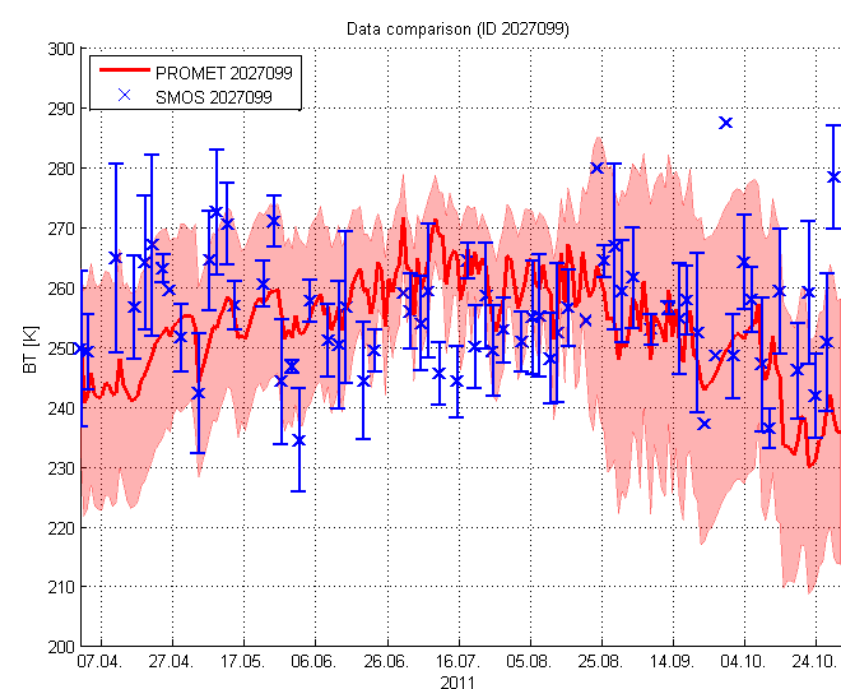

Fig. 7. The time series of modelled and SMOS L1c brightness temperatures for April to October 2011 for the $20^{\circ}$ look angle and vertical polarisation for the central ISEA grid point in the Vils test site. Error bars indicate \pm one standard deviation for angular (SMOS) and spatial (model) averaging.

get better with increasing look angle, except for the $10^{\circ}$ angle. The vertical polarisation behaves similarly. These correlations are generally lower than the correlations between PROMET and SMOS L2 soil moisture which is 0.57 for the ID 2027099 in 2011 (dall'Amico, 2012). Concerning regressions (gain) and RMSE values the vertically polarised brightness temperatures perform better than the horizontally polarised ones. The bias for the horizontal polarisation increases with increasing look angles. The regressions for the vertical polarisation improve with increasing angles, this is not as pronounced for the other polarisation. Following radiative transfer theory, the horizontally polarised brightness temperatures are expected to decrease with increasing look angle, while the vertically polarised ones are expected to be generally higher and increase with increasing look angles. The expected behaviour is only observable for the vertically polarised observations. The model data shows the expected behaviour.

In general the horizontally polarised brightness temperatures seem less reliable than the vertically polarised ones and the lower look angles perform inferior to the higher angles. One has to keep in mind that the significance of the results for the angles below $30^{\circ}$ is lower due to the smaller sample size. The lower performance of SMOS data for the lower look angles is consistent with findings of Bircher et al. (2012) and may be related to the SMOS interferometric imaging technique.

Figures 5 to 8 show both time series for the $20^{\circ}$ and $40^{\circ}$ look angles for both polarisations from April to October 2011 and Figs. 9 to 12 show the scatter plots for the same comparisons. The error bars in Figs. 5 to 8 represent the standard

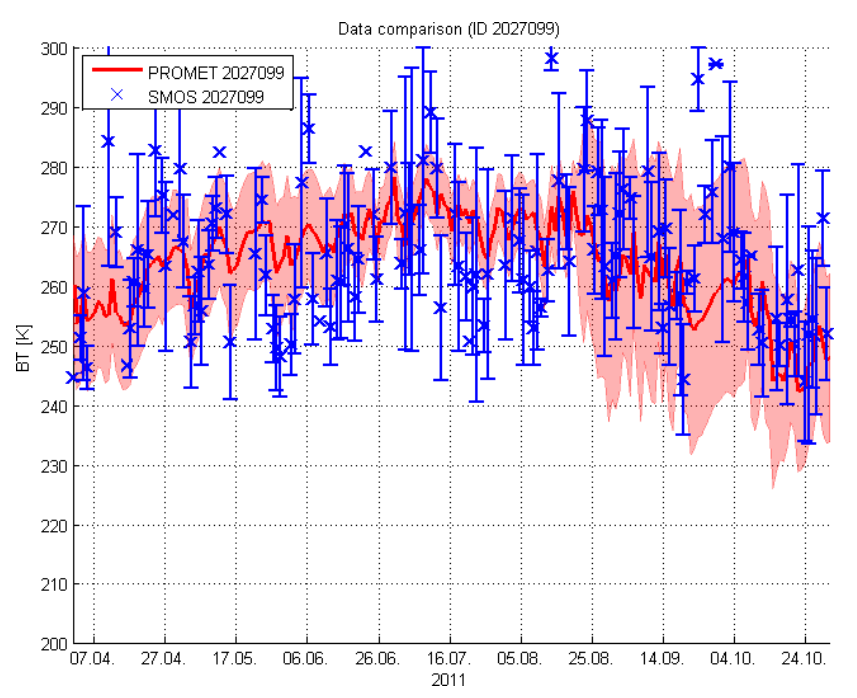

Fig. 8. The time series of modelled and SMOS L1c brightness temperatures for April to October 2011 for the $40^{\circ}$ look angle and vertical polarisation for the central ISEA grid point in the Vils test site. Error bars indicate \pm one standard deviation for angular (SMOS) and spatial (model) averaging.

deviation of the spatial (models) and angular (SMOS) averaging of the data. The model standard deviations are relatively large due to the high spatial resolution of the models which leads to very different land cover classes being averaged (e.g., bare soil and forest). The model standard deviations are smaller in the summer months from around mid-June to mid-August because the optical depth variations are smaller during this time as most crops have relatively high LAI values (compare Fig. 13). In August, winter wheat is being harvested leaving bare soil fields while maize shows very high LAI values, therefore, the standard deviation increases substantially. The behaviour of the additional look angles, that were modelled, is analogue to the $20^{\circ}$ and $40^{\circ}$ comparisons (not shown). Due to orbit geometry there are less SMOS observations available for $20^{\circ}$ than for $40^{\circ}$. For the angles $10^{\circ}$ to $30^{\circ}$ in the horizontal polarisation the SMOS brightness temperatures are considerably lower than the modelled ones for the summer months between end of May and end of August. For the other months it is the other way round for all angles. For the angles $40^{\circ}$ and $50^{\circ}$ both datasets have comparable mean values for the summer months. For vertical polarisation the behaviour is similar. If the other two ISEA IDs in the Vils test site 2026586 and 2026587 are considered the big picture for the brightness temperature comparison is very similar but the performance concerning correlation, RMSE and regression tends to be lower (not shown), which is analogue to SMOS L2 soil moisture data performance.

The seasonal behaviour of SMOS is not as expected. The expected increase of brightness temperatures in summer due to higher soil temperatures is not clearly visible due to a 
Table 2. The statistics for the comparison of SMOS L1c and modelled brightness temperature for different look angles and both polarisations for the central ISEA ID in the Vils test site (2027099) for April to October 2011. $R$ is the correlation coefficient, RMSE the root-mean-squared error, gain and bias are the parameters from the regression line and $N$ is the sample size.

\begin{tabular}{|c|c|c|c|c|c|c|c|}
\hline $\begin{array}{l}\text { Look } \\
\text { angle }\end{array}$ & $\begin{array}{r}R \\
{[-]}\end{array}$ & $\begin{array}{r}\text { RMSE } \\
{[\mathrm{K}]}\end{array}$ & $\begin{array}{r}\text { Gain } \\
{[-]}\end{array}$ & $\begin{array}{l}\text { Bias (SMOS - } \\
\text { PROMET) [K] }\end{array}$ & $\begin{array}{l}\text { Mean (STDV) } \\
\text { SMOS [K] }\end{array}$ & $\begin{array}{l}\text { Mean (STDV) } \\
\text { PROMET [K] }\end{array}$ & $N$ \\
\hline TBH10 & 0.17 & 12.09 & 0.14 & -4.13 & 245.24 (7.86) & 249.37 (8.97) & 35 \\
\hline ТВH20 & 0.13 & 13.14 & 0.13 & 1.0 & 248.97 (10.24) & $247.97(9.47)$ & 67 \\
\hline TBH30 & 0.29 & 12.46 & 0.27 & 4.04 & $249.68(9.79)$ & 245.64 (10.39) & 99 \\
\hline TBH40 & 0.3 & 17.69 & 0.27 & 11.58 & $254.08(10.82)$ & $242.50(11.91)$ & 130 \\
\hline TBH50 & 0.41 & 21.82 & 0.33 & 17.94 & 256.85 (11.05) & $238.91(14.20)$ & 77 \\
\hline TBV10 & 0.29 & 10.50 & 0.25 & 2.73 & $252.97(8.21)$ & $250.24(8.65)$ & 35 \\
\hline TBV20 & 0.1 & 12.71 & 0.11 & 2.35 & 255.66 (9.93) & $253.31(8.60)$ & 67 \\
\hline TBV30 & 0.3 & 11.38 & 0.38 & 1.05 & $259.03(10.63)$ & $257.98(8.40)$ & 99 \\
\hline TBV40 & 0.39 & 10.99 & 0.56 & 0.94 & 264.69 (11.30) & $263.75(7.83)$ & 130 \\
\hline TBV50 & 0.36 & 12.77 & 0.66 & -5.52 & 264.57 (12.32) & $270.09(6.77)$ & 77 \\
\hline
\end{tabular}

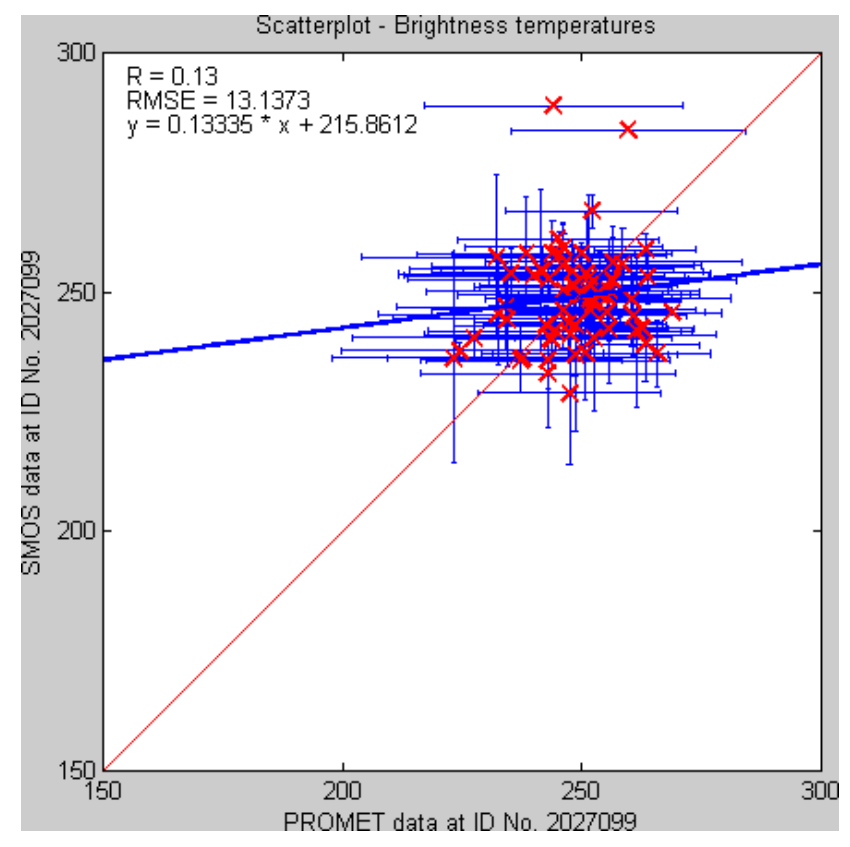

Fig. 9. Scatter plot for the comparison of modelled vs. SMOS L1c brightness temperatures for the look angle $\mathrm{H} 20^{\circ}$.

sharp drop in brightness temperatures at the beginning of June. This seasonal behaviour is not observable in the model data that serve as input for L-MEB. Soil moisture modelling for example seems to work equally well before and after the drop (Fig. 3). The drop in brightness temperatures coincides roughly with the increase in soil moisture at end of the pronounced drying period in April and May, but obviously the model data does not react as extreme to the increase in soil moisture as the SMOS data.

As the correlations between SMOS L1c and modelled brightness temperatures are inferior to the correlations between SMOS L2 and modelled soil moisture, the problems in the SMOS L2 soil moisture product are considered to originate not exclusively from a retrieval problem. A pure

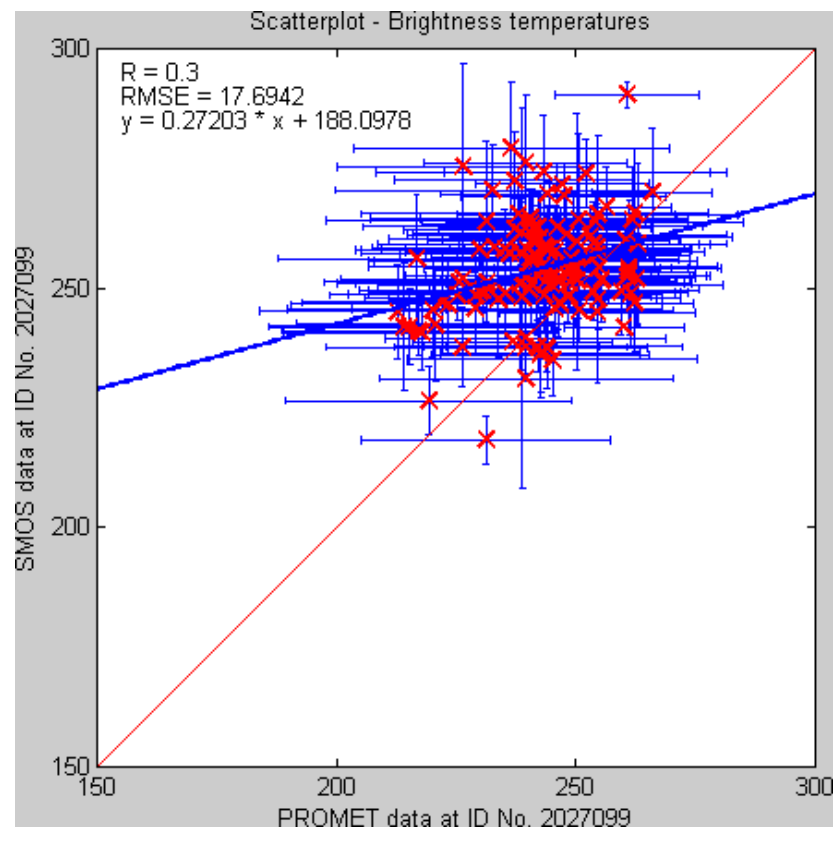

Fig. 10. Scatter plot for the comparison of modelled vs. SMOS L1c brightness temperatures for the look angle $\mathrm{H} 40^{\circ}$.

retrieval problem would mainly be visible in the L2 data, but not in L1c data, if the radiative transfer modelling works reliably. As it was shown in Sect. 4.1 that the radiative transfer modelling works reliably under most conditions in the study area, this points towards an RFI issue because it affects both L1c and L2 data. The mean positive bias in the SMOS brightness temperatures (compare Table 2) adds to this argumentation (Oliva et al., 2012) state that RFI can produce higher SMOS brightness temperatures which would lead to a dry bias in the soil moisture retrievals. The mean positive bias in the SMOS brightness temperatures can partly explain the observed dry bias in the SMOS L2 soil moisture products, that were found by dall'Amico (2012). A more pronounced overestimation of brightness temperatures would be 


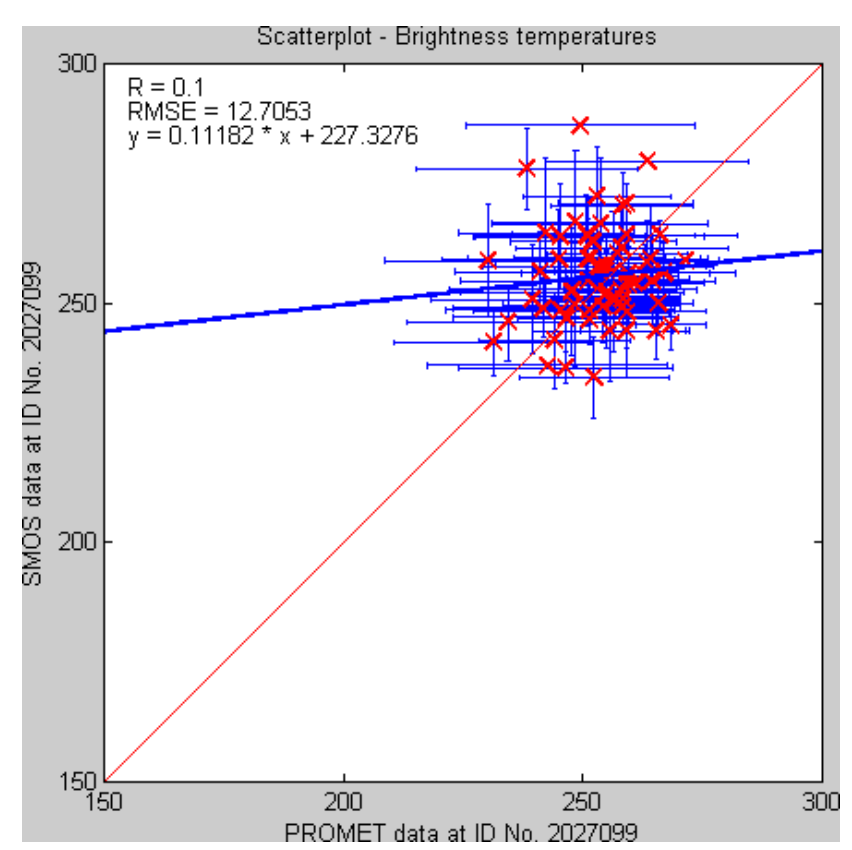

Fig. 11. Scatter plot for the comparison of modelled vs. SMOS L1c brightness temperatures for the look angle $\mathrm{V} 20^{\circ}$.

necessary to explain it entirely. However, as the SMOS L1c data processing described in Sect. 2.3 uses stricter filtering techniques than the official SMOS processor, it is possible that the bias is decreased due to a more efficient filtering of RFI. Of course other factors can also add to the RFI induced problems. These comprise unresolved scaling issues in the radiative transfer modelling, non-RFI induced retrieval problems or even sensor accuracy, or calibration issues. As the SMOS soil moisture performs very well in other parts of the world these factors are considered to play a minor role here.

Of course this comparison involves the same approximations that are mentioned in the previous section that are related to the different geometries of the datasets compared. But due to the already demonstrated homogeneity of the Vils test site (see Sect. 4.1), this is not expected to have a substantial impact.

For the interpretation of these results it is important to keep the uncertainties in mind that are related to the modelling approach. In Sect. 3.1.1 it is shown that the uncertainties of the land surface model have been assessed thoroughly and are considered to be small. Soil moisture, temperature and vegetation modelling work reliably. The radiative transfer modelling uncertainties are assessed in Sect. 3.1.2 in May and June 2010 in the study area. Under contrasting soil moisture, vegetation and temperature conditions the model works reliably with brightness temperature RMSE values between $6 \mathrm{~K}$ and $9 \mathrm{~K}$. The comparisons in this section show considerably larger deviations during the same time of year. As both results were obtained under similar conditions in the same area, the radiative transfer modelling uncertainties are considered to play a minor role here.

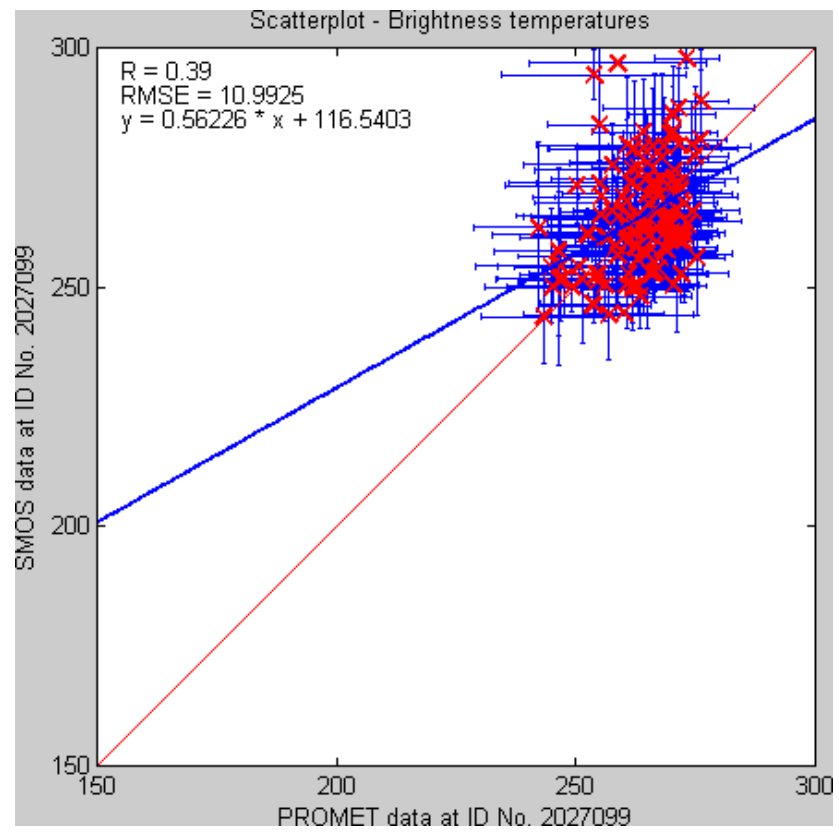

Fig. 12. Scatter plot for the comparison of modelled vs. SMOS L1c brightness temperatures for the look angle $\mathrm{V} 40^{\circ}$.

\subsection{Analysis of SMOS optical depth Tau}

As the vegetation optical depth plays an important role in the SMOS soil moisture retrieval and could prove to be a valuable source of information about vegetation characteristics, it has been analysed for the year 2011. Figure 13 shows the time series of the comparison between modelled and SMOS L2 optical depth for low vegetation for April to October 2011 at the central ISEA ID in the Vils test site. Error bars indicate the data quality index value (DQX) for SMOS and the standard deviation of the averaging for the models. Analogue to the brightness temperatures, the model standard deviations are relatively high due to the high spatial resolution of the models. The correlation coefficient for this comparison is 0.33 and the bias (SMOS - model) 0.18. When considering the additional two ISEA IDs in the Vils test site, SMOS values are generally too high although the correlation coefficients differ for the IDs (correlation coefficient: -0.27 and 0.03 for ID 2026587 and 2026586, respectively; bias: 0.10 and 0.13 for ID 2026587 and 2026586, respectively) (not shown). The seasonal behaviour is different from ID to ID, while some features are similar. The seasonal pattern of vegetation optical depth for a temperate region with a high percentage of crops consists of an increase from spring until summer during the crop growth phase and a decrease in fall during ripening and harvesting. This is not clearly apparent in the SMOS data. The increase in April and May seems to be captured as well as a decrease in October, but the variability of SMOS optical depth appears very high with several peaks throughout the year compared to typical vegetation 


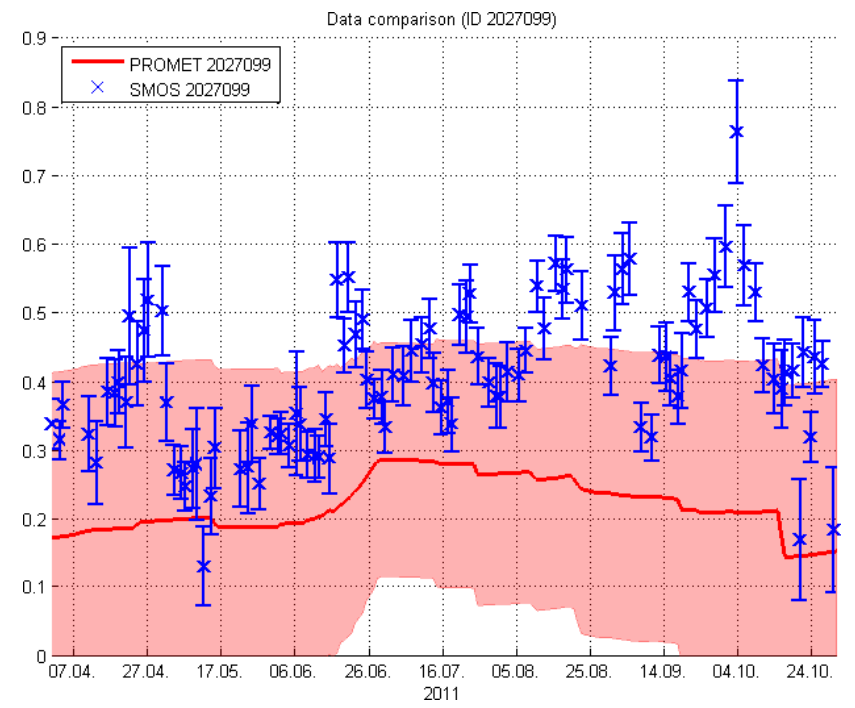

Fig. 13. A comparison between modelled (red) and SMOS L2 optical depth (blue) for the central ISEA ID in the Vils test site. Both values are valid for the nominal land use class (low vegetation). Error bars indicate \pm the DQX value for SMOS and the standard deviation for the spatial averaging for PROMET.

phenology. The mean value of 0.40 is relatively high when compared to model simulations and typical values found in literature that range between maximum values of 0.3 and 0.4 for low vegetation (Wigneron et al., 2007; Saleh et al., 2007). A visual comparison to MODIS NDVI data from (ORNLDAAC, 2012) did not deliver any similarity with SMOS optical depth either. It does not seem to have a physical meaning which was also found by Jackson et al. (2012) in the US. The high variability, the unclear seasonal pattern and the high values of optical depth could indicate that SMOS optical depth also depends on other parameters than vegetation. To test whether there is a relationship between SMOS retrieved soil moisture and optical depth, both datasets were compared. Although a visual comparison of the time series does not allow any conclusions, the scatter plot (Fig. 14) shows a clear relationship with a correlation coefficient of 0.65 , which is similar for the other Vils IDs. This is the largest correlation coefficient determined in the whole study per se and surprising as soil moisture and optical depth are considered independent variables in our area. Modelled soil moisture and optical depth show no significant correlation $(R=0.053)$ for the same comparison.

Obviously the retrieval does not work reliably. Whether this is only due to the RFI problems in the L1c data, causing retrieval problems in any case, or also to additional factors remains unclear. Possibly parameters in the radiative transfer modelling that are compensated by Tau could play a role here.

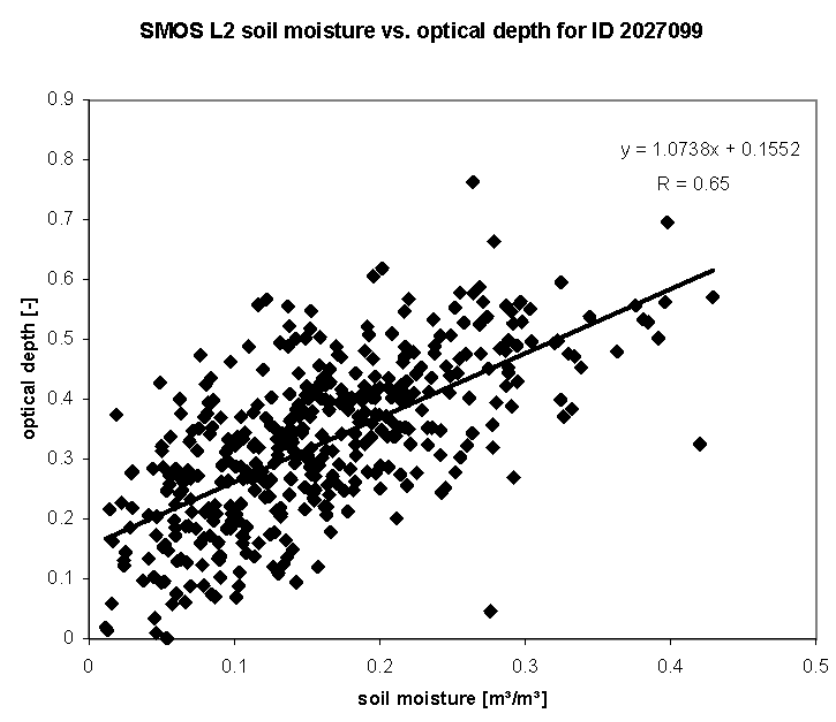

Fig. 14. Scatter plot for the comparison between SMOS L2 soil moisture and optical depth for the ID 2027099.

\section{Conclusion and outlook}

The land surface model PROMET and the radiative transfer model L-MEB have been coupled and used as a tool for the analysis of SMOS passive microwave satellite observations. The coupled models have been shown to work well in determining the L-band microwave emission under varying soil moisture, vegetation and temperature conditions during the SMOS Validation Campaign 2010. Their output has been compared to ground data and airborne L-band brightness temperature measurements. The brightness temperature RMSE is around $6 \mathrm{~K}-9 \mathrm{~K}$. Therefore, the L-MEB parameterisations used in this study are considered reliable enough to be used for SMOS validation activities. However, a further optimisation under local conditions may still be possible. A known uncertainty factor that should further be investigated is the brightness temperature behaviour shortly after precipitation events.

SMOS L1c brightness temperature data have been compared to airborne brightness temperatures on two days during the SMOS Validation Campaign 2010 from which no reliable conclusions can be drawn due to the small dataset.

An extensive comparison of SMOS L1c with modelled brightness temperatures from April to October 2011 was performed in the Vils test site. SMOS L1c brightness temperatures do not show the expected seasonal behaviour and are positively biased. SMOS L1c data do not perform better than L2 soil moisture data in the Vils test site, which could have pointed towards a pure retrieval problem. It is concluded that RFI most probably contributes considerably to the observed problems in the SMOS L2 soil moisture product. This is consistent with the observed dry bias in the SMOS L2 soil moisture products which can be related to RFI as stated by Oliva et 
al. (2012). Still, other factors could also contribute to the observed problems. These comprise unresolved scaling issues in the radiative transfer modelling, non-RFI induced retrieval problems or even sensor accuracy, or calibration issues, although they are considered to play a minor role. It is confirmed that the brightness temperature data from the lower SMOS look angles are less reliable which has also been reported by Bircher et al. (2012). In addition to that the horizontally polarised brightness temperatures perform inferior to the vertically polarised ones. This information could be used to improve the brightness temperature data filtering before the SMOS soil moisture retrieval.

SMOS L2 optical depth values have been compared to modelled data using vegetation parameters from the dynamic vegetation model in PROMET. SMOS optical depth does not seem to be a reliable source of information about vegetation characteristics due to missing seasonal behaviour and very high values. A strong correlation between SMOS L2 soil moisture and optical depth was found that was not expected $(R=0.65)$. This points clearly towards retrieval problems which is not surprising with the apparent RFI. This should be further investigated. As it has been shown that RFI probably is responsible for a considerable part of the observed problems RFI mitigation efforts should be continued to improve SMOS data quality.

The clear improvement in SMOS L2 soil moisture performance from 2010 to 2011 that is shown by dall'Amico et al. (2012a) and dall'Amico (2012) demonstrates that significant improvements in the performance of the SMOS satellite products are possible during the first years of such a mission. In other parts of the world, the SMOS L2 soil moisture product performs very well (Jackson et al., 2012) e.g., state that the RMSE of the comparison between SMOS L2 soil moisture and measurements in four catchments in the US are $0.043 \mathrm{~m}^{3} \mathrm{~m}^{-3}$. This demonstrates that the SMOS soil moisture retrieval can work very reliably if there is no RFI even though Jackson et al. (2012) also found problems with the vegetation optical depth. To study the potential origin of problems in the SMOS L2 soil moisture product, coupled land surface and radiative transfer models are helpful.

The value of coupled land surface and radiative transfer models for the validation and analysis of passive microwave remote-sensing data has been shown in this study. The models made an extensive SMOS data analysis possible that would have been limited to a few days of distributed ground and airborne data without them. Even though an extensive field campaign was conducted, hardly any conclusions could be drawn from this without the models.

In a next step the coupled models could be used for different soil moisture retrievals from SMOS L1c data to assess the potential of improvements in the SMOS L2 soil moisture product.
Acknowledgements. The SMOS Validation Campaign 2010 was organised and funded by the ESA with the indispensable contribution of the teams of the Aalto University and the Technical University of Denmark. The authors wish to acknowledge the contributions of the students of the University of Munich helping with the in situ measurements and the assistance given by Timo Gebhardt in the data processing. The authors would like to thank J.-P. Wigneron for making the model L-MEB available. The ELBARA instrument was kindly provided by ESA. Meteorological data and technical and logistical support in running the soil moisture stations were kindly provided by the Bavarian State Research Center for Agriculture, Department Meteorology (Mr. Kerscher), which is gratefully acknowledged. This work was supported by the German Federal Ministry of Economics and Technology through the German Aerospace Center (DLR, 50 EE 0731) which is gratefully acknowledged. Alexander Loew was supported by the Cluster of Excellence "CliSAP" (EXC177), University of Hamburg, funded through the German Science Foundation (DFG). I would like to thank the anonymous referees for their valuable comments that helped to improve the paper.

Edited by: W. Wagner

\section{References}

Albergel, C., Calvet, J.-C., de Rosnay, P., Balsamo, G., Wagner, W., Hasenauer, S., Naeimi, V., Martin, E., Bazile, E., Bouyssel, F., and Mahfouf, J.-F.: Cross-evaluation of modelled and remotely sensed surface soil moisture with in situ data in southwestern France, Hydrol. Earth Syst. Sci., 14, 2177-2191, doi:10.5194/hess-14-2177-2010, 2010.

Albergel, C., Zakharova, E., Calvet, J.-C., Zribi, M., Pardé, M., Wigneron, J.-P., Novello, N., Kerr, Y., Mialon, A., and Fritz, N.-E.-D.: A first assessment of the SMOS data in southwestern France using in situ and airborne soil moisture estimates: The CAROLS airborne campaign, Remote Sens. Environ., 115, 2718-2728, doi:10.1016/j.rse.2011.06.012, 2011.

Albergel, C., de Rosnay, P., Gruhier, C., Muñoz-Sabater, J., Hasenauer, S., Isaksen, L., Kerr, Y., and Wagner, W.: Evaluation of remotely sensed and modelled soil moisture products using global ground-based in situ observations, Remote Sens. Environ., 118, 215-226, doi:10.1016/j.rse.2011.11.017, 2012.

Bach, H. and Mauser, W.: Methods and examples for remote sensing data assimilation in land surface process modeling, IEEE T. Geosci. Remote Sens., 41, 1629-1637, 2003.

Bach, H., Braun, M., Lampart, G., and Mauser, W.: Use of remote sensing for hydrological parameterisation of Alpine catchments, Hydrol. Earth Syst. Sci., 7, 862-876, doi:10.5194/hess-7-8622003, 2003.

Balling, J. E., Kristensen, S. S., Sobjaerg, S. S., and Skou, N.: Surveys and Analysis of RFI in Preparation for SMOS: Results from Airborne Campaigns and First Impressions from Satellite Data, IEEE T. Geosci. Remote Sens., 49, 4821-4831, 2011.

Bartalis, Z., Wagner, W., Anderson, C., Bonekamp, H., Naeimi, V., and Hasenauer, S.: Validation of Coarse Resolution Microwave Soil Moisture Products, Geoscience and Remote Sensing Symposium (IGARSS), IEEE International, II-173-II-176, 2008.

Bircher, S., Balling, J. E., Skou, N., and Kerr, Y. H.: Validation of SMOS Brightness Temperatures During the HOBE Airborne 
Campaign, Western Denmark, IEEE T. Geosci. Remote Sens., 50, 1468-1482, doi:10.1109/tgrs.2011.2170177, 2012.

Bolten, J. D., Crow, W. T., Xiwu, Z., Jackson, T. J., and Reynolds, C. A.: Evaluating the Utility of Remotely Sensed Soil Moisture Retrievals for Operational Agricultural Drought Monitoring, IEEE J. Sel. Top. Appl., 3, 57-66, 2010.

Brooks, R. and Corey, A.: Hydraulic properties of porous media, Tech. rep., Hydrology paper 3. Colorado State University, Fort Collins, Colorado, 1964.

BÜK: 1000 Bodenübersichtskarte Deutschland 1:1000000, available at: http://www.bgr.bund.de/DE/Themen/Boden/Produkte/ produktkatalog_node.html (last access: 4 October 2012), 1997.

Crow, W. T., Ryu, D., and Famiglietti, J. S.: Upscaling of field-scale soil moisture measurements using distributed land surface modeling, Adv. Water Res., 28, 1-14, doi:10.1016/j.advwatres.2004.10.004, 2005.

dall'Amico, J. T.: Multiscale analysis of soil moisture using satellite and aircraft microwave remote sensing, in situ measurements and numerical modeling, Phd, Department for Geography, Ludwig Maximilians University, Munich, Germany, 2012.

dall'Amico, J. T., Schlenz, F., Loew, A., and Mauser, W.: First Results of SMOS Soil Moisture Validation in the Upper Danube Catchment, IEEE T. Geosci. Remote Sens., 50, 1507-1516, doi:10.1109/tgrs.2011.2171496, 2012a.

dall'Amico, J. T., Schlenz, F., Loew, A., Mauser, W., Kainulainen, J., Balling, J., and Bouzinac, C.: The SMOS Validation Campaign 2010 in the Upper Danube Catchment: A Data Set for Studies of Soil Moisture, Brightness Temperature and their Spatial Variability over a Heterogeneous Land Surface, IEEE T. Geosci. Remote Sens., 99, 1-14, doi:10.1109/TGRS.2012.2196523, $2012 b$

Delwart, S., Bouzinac, C., Wursteisen, P., Berger, M., Drinkwater, M., Martin-Neira, M., and Kerr, Y. H.: SMOS Validation and the COSMOS Campaigns, IEEE T. Geosci. Remote Sens., 46, 695704, 2008.

Dirmeyer, P. A.: Using a Global Soil Wetness Dataset to Improve Seasonal Climate Simulation, J. Climate, 13, 2900-2922, doi:10.1175/1520-0442(2000)013<2900:UAGSWD>2.0.CO;2, 2000.

Dorigo, W. A., Wagner, W., Hohensinn, R., Hahn, S., Paulik, C., Xaver, A., Gruber, A., Drusch, M., Mecklenburg, S., van Oevelen, P., Robock, A., and Jackson, T.: The International Soil Moisture Network: a data hosting facility for global in situ soil moisture measurements, Hydrol. Earth Syst. Sci., 15, 1675-1698, doi:10.5194/hess-15-1675-2011, 2011.

Entekhabi, D., Asrar, G. R., Betts, A. K., Beven, K. J., Bras, R. L., Duffy, C. J., Dunne, T., Koster, R. D., Lettenmaier, D. P., Mclaughlin, D. B., Shuttleworth, W. J., Van Genuchten, M. T., Wei, M.-Y., and Wood, E. F.: An agenda for land-surface hydrology research and a call for the second international hydrological decade, B. Am. Meteorol. Soc., 80, 2043-2057, 1999.

ESA: Mission Objectives and Scientific Requirements of the Soil Moisture and Ocean Salinity (SMOS) Mission, Version 5, European Space Agency (ESA), 2002.

Grant, J. P., Wigneron, J. P., Van de Griend, A. A., Kruszewski, A., Søbjærg, S. S., and Skou, N.: A field experiment on microwave forest radiometry: L-band signal behaviour for varying conditions of surface wetness, Remote Sens. Environ., 109, 10-19, doi:10.1016/j.rse.2006.12.001, 2007.
Gruhier, C., Pellarin, T., de Rosnay, P., and Kerr, Y.: SMOS soil moisture product evaluation over West-Africa at local and regional scale, Remote Sens. Environ., under review, 2012.

Hank, T.: A Biophysically Based Coupled Model Approach for the Assessment of Canopy Processes under Climate Change Conditions, Phd, Department for Geography, Ludwig Maximilians University, Munich, Germany, 2008.

Hornbuckle, B. K., Rowlandson, T. L., Patton, J. C., and Bramer, L. M.: How is the angular signature of SMOS brightness temperature different in the morning and evening?, Geoscience and Remote Sensing Symposium (IGARSS), IEEE International, 31253128, 2011.

Jackson, T. J., Bindlish, R., Cosh, M. H., Zhao, T., Starks, P. J., Bosch, D. D., Seyfried, M., Moran, M. S., Goodrich, D. C., Kerr, Y. H., and Leroux, D.: Validation of Soil Moisture and Ocean Salinity (SMOS) Soil Moisture Over Watershed Networks in the US, IEEE T. Geosci. Remote Sens., 50, 1530-1543, doi:10.1109/tgrs.2011.2168533, 2012.

Juglea, S., Kerr, Y., Mialon, A., Wigneron, J.-P., Lopez-Baeza, E., Cano, A., Albitar, A., Millan-Scheiding, C., Carmen Antolin, M., and Delwart, S.: Modelling soil moisture at SMOS scale by use of a SVAT model over the Valencia Anchor Station, Hydrol. Earth Syst. Sci., 14, 831-846, doi:10.5194/hess-14-831-2010, 2010.

Kerr, Y. H., Waldteufel, P., Wigneron, J. P., Delwart, S., Cabot, F., Boutin, J., Escorihuela, M. J., Font, J., Reul, N., Gruhier, C., Juglea, S. E., Drinkwater, M. R., Hahne, A., Martin-Neira, M., and Mecklenburg, S.: The SMOS Mission: New Tool for Monitoring Key Elements ofthe Global Water Cycle, P. IEEE, 98, 666-687, 2010.

Kerr, Y. H., Waldteufel, P., Richaume, P., Davenport, P., Ferrazzoli, P., and Wigneron, J.-P.: SMOS level 2 processor soil moisture algorithm theoretical basis document (ATBD) V 3.5, CBSA, UoR, TV and INRA, Toulouse, 2011.

Loew, A.: Impact of surface heterogeneity on surface soil moisture retrievals from passive microwave data at the regional scale: The Upper Danube case, Remote Sens. Environ., 112, 231-248, doi:10.1016/j.rse.2007.04.009, 2008.

Loew, A. and Schlenz, F.: A dynamic approach for evaluating coarse scale satellite soil moisture products, Hydrol. Earth Syst. Sci., 15, 75-90, doi:10.5194/hess-15-75-2011, 2011.

Loew, A., Ludwig, R., and Mauser, W.: Derivation of surface soil moisture from ENVISAT ASAR wide swath and image mode data in agricultural areas, IEEE T. Geosci. Remote Sens., 44, 889-899, 2006.

Ludwig, R. and Mauser, W.: Modelling catchment hydrology within a GIS based SVAT-model framework, Hydrol. Earth Syst. Sci., 4, 239-249, doi:10.5194/hess-4-239-2000, 2000.

Ludwig, R., Mauser, W., Niemeyer, S., Colgan, A., Stolz, R., Escher-Vetter, H., Kuhn, M., Reichstein, M., Tenhunen, J., Kraus, A., Ludwig, M., Barth, M., and Hennicker, R.: Web-based modelling of energy, water and matter fluxes to support decision making in mesoscale catchments - the integrative perspective of GLOWA-Danube, Phys. Chem. Earth, 28, 621-634, citeulikearticle-id:2923875, 2003.

Mauser, W. and Bach, H.: PROMET - Large scale distributed hydrological modelling to study the impact of climate change on the water flows of mountain watersheds, J. Hydrol., 376, 362377, 2009. 
Mauser, W. and Schädlich, S.: Modelling the spatial distribution of evapotranspiration on different scales using remote sensing data, J. Hydrol., 212-213, 250-267, doi:10.1016/s00221694(98)00228-5, 1998.

Miralles, D. G., Crow, W. T., and Cosh, M. H.: Estimating Spatial Sampling Errors in Coarse-Scale Soil Moisture Estimates Derived from Point-Scale Observations, J. Hydrometeorol., 11, 1423-1429, doi:10.1175/2010JHM1285.1, 2010.

Montzka, C., Bogena, H., Weihermueller, L., Jonard, F., Dimitrov, M., Bouzinac, C., Kainulainen, J., Balling, J. E., Vanderborght, J., and Vereecken, H.: Radio brightness validation on different spatial scales during the SMOS validation campaign 2010 in the Rur catchment, Germany, Geoscience and Remote Sensing Symposium (IGARSS), IEEE International, 3760-3763, 2011.

Muerth, M.: A Soil Temperature and Energy Balance Model for Integrated Assessment of Global Change Impacts at the regional scale, Phd, Department for Geography, Ludwig Maximilians University, Munich, Germany, 2008.

Oliva, R., Daganzo-Eusebio, E., Kerr, Y. H., Mecklenburg, S., Nieto, S., Richaume, P., and Gruhier, C.: SMOS Radio Frequency Interference Scenario: Status and Actions Taken to Improve the RFI Environment in the 1400\&\#x02013;1427-MHz Passive Band, IEEE T. Geosci. Remote Sens., 50, 1427-1439, doi:10.1109/tgrs.2012.2182775, 2012.

ORNL-DAAC: MODIS subsetted land products, Collection 5, available at: http://daac.ornl.gov/MODIS/modis.html (last access: 9 February 2012), 2012.

Panciera, R., Walker, J. P., and Merlin, O.: Improved Understanding of Soil Surface Roughness Parameterization for L-Band Passive Microwave Soil Moisture Retrieval, IEEE Geosci. Remote S., 6, 625-629, 2009.

Parrens, M., Zakharova, E., Lafont, S., Calvet, J.-C., Kerr, Y., Wagner, W., and Wigneron, J.-P.: Comparing soil moisture retrievals from SMOS and ASCAT over France, Hydrol. Earth Syst. Sci., 16, 423-440, doi:10.5194/hess-16-423-2012, 2012.

Pauwels, V. R. N., Timmermans, W., and Loew, A.: Comparison of the estimated water and energy budgets of a large winter wheat field during AgriSAR 2006 by multiple sensors and models, J. Hydrol., 349, 425-440, doi:10.1016/j.jhydrol.2007.11.016, 2008.

Philip, J.: The theory of infiltration: 1. the infiltration equation and its solution, Soil Sci., 83, 345-357, 1957.

Prigent, C., Aires, F., Rossow, W. B., and Robock, A.: Sensitivity of satellite microwave and infrared observations to soil moisture at a global scale: Relationship of satellite observations to in situ soil moisture measurements, J. Geophys. Res., 110, D07110, doi:10.1029/2004jd005087, 2005.

Probeck, M., Ludwig, R., and Mauser, W.: Fusion of NOAAAVHRR imagery and geographical information system techniques to derive subscale land cover information for the upper Danube watershed, Hydrol. Process., 19, 2407-2418, doi:10.1002/hyp.5892, 2005.
Rowlandson, T. L., Hornbuckle, B. K., Bramer, L. M., Patton, J. C., and Logsdon, S. D.: Comparisons of Evening and Morning SMOS Passes Over the Midwest United States, IEEE T. Geosci. Remote Sens., 50, 1544-1555, doi:10.1109/tgrs.2011.2178158, 2012.

Saleh, K., Wigneron, J. P., Waldteufel, P., de Rosnay, P., Schwank, M., Calvet, J. C., and Kerr, Y. H.: Estimates of surface soil moisture under grass covers using L-band radiometry, Remote Sens. Environ., 109, 42-53, doi:10.1016/j.rse.2006.12.002, 2007.

Saleh, K., Kerr, Y. H., Richaume, P., Escorihuela, M. J., Panciera, R., Delwart, S., Boulet, G., Maisongrande, P., Walker, J. P., Wursteisen, P., and Wigneron, J. P.: Soil moisture retrievals at L-band using a two-step inversion approach (COSMOS/NAFE'05 Experiment), Remote Sens. Environ., 113, 1304-1312, doi:10.1016/j.rse.2009.02.013, 2009.

Schlenz, F., dall'Amico, J. T., Loew, A., and Mauser, W.: Uncertainty Assessment of the SMOS Validation in the Upper Danube Catchment, IEEE T. Geosci. Remote Sens., 50, 1517-1529, doi:10.1109/tgrs.2011.2171694, 2012a.

Schlenz, F., Fallmann, J., Marzahn, P., Loew, A., and Mauser, W.: Characterization of Rape Field Microwave Emission and Implications to Surface Soil Moisture Retrievals, Remote Sensing, 4, 247-270, 2012b.

Schwank, M., Wiesmann, A., Werner, C., Mätzler, C., Weber, D., Murk, A., Völksch, I., and Wegmüller, U.: ELBARA II, an LBand Radiometer System for Soil Moisture Research, Sensors, 10, 584-612, 2009.

Skou, N., Misra, S., Balling, J. E., Kristensen, S. S., and Sobjaerg, S. S.: L-Band RFI as Experienced During Airborne Campaigns in Preparation for SMOS, IEEE T. Geosci. Remote Sens., 48, 1398-1407, 2010.

Strasser, U. and Mauser, W.: Modelling the spatial and temporal variations of the water balance for the Weser catchment 1965-1994, J. Hydrol., 254, 199-214, doi:10.1016/s00221694(01)00492-9, 2001.

Strasser, G., Schneider, K., and Mauser, W.: The use of ERS SAR data derived soil moisture distributions for SVAT-model validation, Int. Geosci. Remote Se., 4, 1921-1923, 1999.

Wigneron, J. P., Kerr, Y., Waldteufel, P., Saleh, K., Escorihuela, M. J., Richaume, P., Ferrazzoli, P., de Rosnay, P., Gurney, R., Calvet, J. C., Grant, J. P., Guglielmetti, M., Hornbuckle, B., Mätzler, C., Pellarin, T., and Schwank, M.: L-band Microwave Emission of the Biosphere (L-MEB) Model: Description and calibration against experimental datasets over crop fields, Remote Sens. Environ., 107, 639-655, doi:10.1016/j.rse.2006.10.014, 2007.

Woodhouse, I. H.: Introduction to microwave remote sensing, Taylor and Francis, London, 2006. 